\title{
Synthesis and Evaluation of Novel Fluorinated 2-Styrylchromones as Antibacterial Agents
}

\author{
Mehbub Momin, ${ }^{1}$ Deresh Ramjugernath, ${ }^{2}$ Hafizah Chenia, ${ }^{3}$ and Neil A. Koorbanally ${ }^{1}$ \\ ${ }^{1}$ School of Chemistry, University of KwaZulu-Natal, Private Bag X54001, Durban 4000, South Africa \\ ${ }^{2}$ School of Chemical Engineering, University of KwaZulu-Natal, Private Bag X54001, Durban 4000, South Africa \\ ${ }^{3}$ Department of Biochemistry, Genetics, and Microbiology, University of KwaZulu-Natal, Private Bag X54001, \\ Durban 4000, South Africa
}

Correspondence should be addressed to Neil A. Koorbanally; koorbanally@ukzn.ac.za

Received 27 May 2013; Revised 8 August 2013; Accepted 16 August 2013

Academic Editor: Hugo Verli

Copyright (C) 2013 Mehbub Momin et al. This is an open access article distributed under the Creative Commons Attribution License, which permits unrestricted use, distribution, and reproduction in any medium, provided the original work is properly cited.

A range of fluorinated 2-styrylchromones $(\mathbf{5 a} \mathbf{a}-\mathbf{g})$ of which six were new $(\mathbf{5 a}-\mathbf{f})$ were prepared in three steps using the BakerVenkataraman rearrangement along with two methoxylated derivatives $(\mathbf{5 h}-\mathbf{i})$ and a methylenedioxy derivative (5j) and screened for their antibacterial activity using Gram-positive bacteria (Staphylococcus aureus, sciuri, and xylosus as well as Bacillus subtilis) and Gram-negative bacteria (Escherichia coli, Pseudomonas aeruginosa, and Klebsiella pneumonia). The compounds were most effective against $B$. subtilis followed by $S$. aureus and a single strain of E. coli (ATCC 25922). Difluorination on the phenyl ring was shown to enhance antibacterial activity, and fluorine substitution at the 6 position was shown to be far superior to substitution at the 7 position. In comparison to tetracycline, the activity indices of the fluorinated styrylchromones ranged from 0.50 to 0.75 against $B$. subtilis. The crystal structure of $2^{\prime}$-fluoro-2-styrylchromone is also presented, and the molecule was shown to be planar.

\section{Introduction}

Fluorinated compounds have a wide range of medical applications such as anti-inflammatory, antiviral, anti-HIV, antibacterial, anticancer, antimalarial, antidepressants, antipsychotics, anaesthetics, and steroids $[1,2]$. Introducing fluorine atoms into drugs can also alter the rate and route of drug metabolism [1], and stereoelectronic factors associated with the fluorine atom can lead to changes in the biological action of molecules in comparison to its hydroxyl or hydrogen analogues [3]. The substitution of fluorine for hydrogen or hydroxy groups can lead to changes in the mechanism of the drug as well as enzyme inhibition [3]. The small size of the fluorine atom, the enhanced lipophilicity it imparts to the molecules, and the electronegativity of the atom often result in improved therapeutic drugs [2]. As part of an ongoing study on fluorinated pharmaceutical compounds, we have chosen to explore the antibacterial effects of fluorinated 2styrylchromones.
The biological activities of 2-styrylchromones have recently been reviewed by Gomes et al. [4]. The 2-styrylchromones were shown to be $\mathrm{A}_{3}$ adenosine receptor antagonists [5], have hepatoprotective activity [6], be potent antioxidants [7], have antiallergic properties [8], antiviral activity [9], and anticancer activity [10-12], and display xanthine oxidase inhibition to treat, for example, gout, hypertension, and hepatitis linked to xanthine oxidase activity [13].

The synthesis of these compounds has been reviewed by Silva et al. [14]. In one synthetic approach, it involves the aldol condensation between cinnamaldehydes and $2^{\prime}$-hydroxyacetophenones followed by an oxidative cyclisation [15]. It was also synthesised by the Baker-Venkataraman rearrangement, involving the $\mathrm{O}$-acylation of $2^{\prime}$-hydroxyacetophenones with cinnamic acids, followed by rearrangement of the ester and then cyclisation into the styrylchromone [16]. They can also be made directly from $2^{\prime}$-hydroxyacetophenones with cinnamoyl chlorides [17]. 

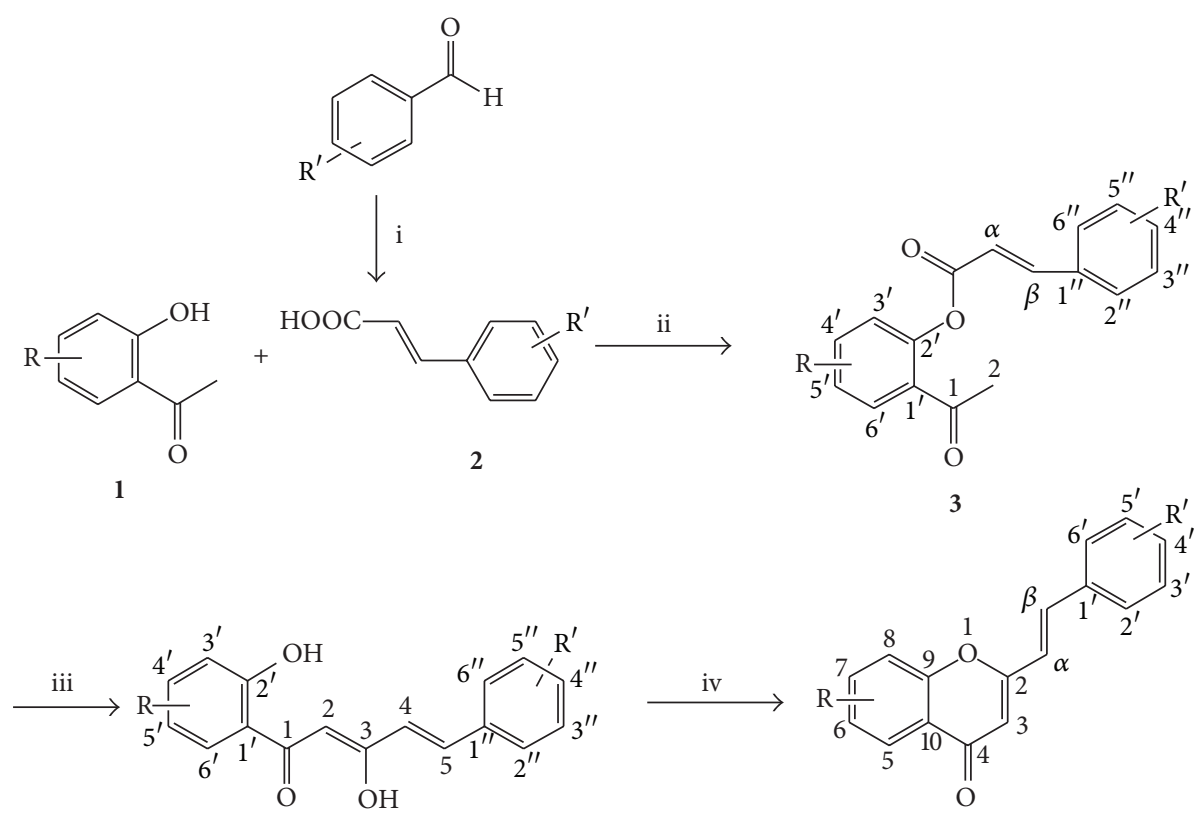

4

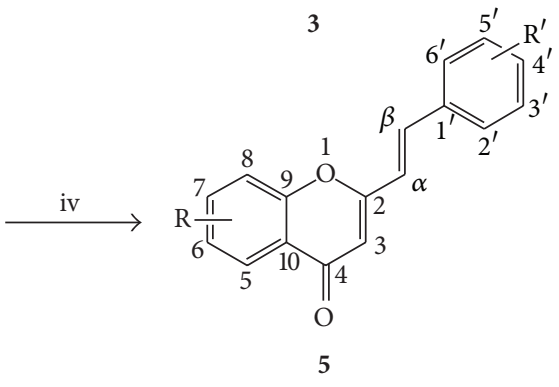
(a) $\mathrm{R}^{\prime}=2^{\prime}-\mathrm{F}$
(b) $\mathrm{R}^{\prime}=3^{\prime}-\mathrm{F}$
(c) $\mathrm{R}^{\prime}=4^{\prime}-\mathrm{F}$
(d) $\mathrm{R}^{\prime}=3^{\prime}, 5^{\prime}-\mathrm{F}$
(e) $\mathrm{R}=7-\mathrm{F}, \mathrm{R}^{\prime}=4^{\prime}-\mathrm{F}$
(f) $\mathrm{R}=7-\mathrm{F}$
(g) $\mathrm{R}=6-\mathrm{F}$
(h) $\mathrm{R}^{\prime}=4^{\prime}-\mathrm{OCH}_{3}$
(i) $\mathrm{R}^{\prime}=3^{\prime}, 4^{\prime}-\mathrm{OCH}_{3}$
(j) $\mathrm{R}^{\prime}=3^{\prime}, 4^{\prime}-\mathrm{OCH}_{2} \mathrm{O}$

FIGURE 1: The preparation of 2-styrylchromones $\mathbf{5 a - j}$ from their corresponding acetophenones and benzaldehydes (i) malonic acid, piperidine, pyridine, $80-90^{\circ} \mathrm{C}, 4-5 \mathrm{~h}$, (ii) pyridine, $\mathrm{POCl}_{3}$, rt. $4-5 \mathrm{~h}$, (iii) DMSO, KOH, rt. $2 \mathrm{~h}$, and (iv) DMSO, PTSA, $90-95^{\circ} \mathrm{C}, 2-3 \mathrm{~h}$.

The 2-styrylchromones have a structure analogous to the flavonoids, with an extra two-carbon olefinic bond between the chromone and the phenyl rings. Thus, instead of a phenyl group attached to the chromone portion as in the flavonoids, a styryl group is inserted instead (see 5 in Figure 1). Due to the double bond in the backbone of the structure, 2styrylchromones are reactive molecules, being able to take part in pericyclic reactions acting as dienes forming xanthones [18] and as dienophiles forming flavones with orthobenzoquinodimethane [19]. They can also be transformed into pyrazolines [20, 21], 1,2,3-triazoles [22], pyrazoles [2325 ], and pyrimidines [26].

To our knowledge, there have only been two studies on fluorinated styrylchromones, where the 6-fluoro styrylchromones have shown antirhinovirus activity [27] and the $4^{\prime}$-fluoro-, the $4^{\prime}$-trifluoromethyl-, and $4^{\prime}$-trifluoromethoxystyrylchromones were shown to have antitumor activity [28]. We report here on the synthesis and antibacterial activity of a series of fluorinated 2-styrylchromones as well as the crystal structure for the $2^{\prime}$-fluoro-2-styrylchromone.

\section{Material and Methods}

2.1. General Experimental Procedures. Reagents and chemicals used in this study were purchased from Sigma Aldrich via Capital Laboratories, South Africa, and were reagent grade. All organic solvents were redistilled and dried according to standard procedures. NMR spectra were recorded using a Bruker Avance ${ }^{\mathrm{III}} 400 \mathrm{MHz}$ spectrometer at room temperature with chemical shifts $(\delta)$ recorded against the internal standard, tetramethylsilane (TMS). 2D NMR spectroscopy (COSY, NOESY, HSQC, and HMBC) were used for the structural elucidation of the synthesised compounds. IR spectra were recorded on a Perkin Elmer Spectrum 100 FTIR spectrometer with universal ATR sampling accessory. For GC-MS analyses, the samples were analysed on an Agilent GC-MSD apparatus equipped with DB-5SIL MS $(30 \mathrm{~m} \times$ $0.25 \mathrm{~mm}$ i.d., $0.25 \mu \mathrm{m}$ film thickness) fused-silica capillary column. Helium (at $2 \mathrm{~mL} \mathrm{~min}^{-1}$ ) was used as a carrier gas. The MS was operated in the EI mode at $70 \mathrm{eV}$. Optical rotation was recorded using a Perkin Elmer, Model 341 Polarimeter. Melting points were recorded on an Ernst Leitz Wetzlar microhot stage melting point apparatus.

2.2. Typical Procedure for the Preparation of Cinnamic Acids. For the preparation of the cinnamic acids $\mathbf{2 a - c}$ and $\mathbf{2 h - i}$, the procedure in Qian et al. [29] was adopted with slight modifications. The required aromatic aldehydes $(3.2 \mathrm{mmol})$, malonic acid $(3.87 \mathrm{mmol})$, and piperidine $(0.387 \mathrm{mmol})$ were dissolved in pyridine $(10 \mathrm{~mL})$ and stirred at $80-90^{\circ} \mathrm{C}$ for 4 5 hours. The pyridine was removed under vacuum, and the reaction mixture was poured into water $(25 \mathrm{~mL})$ and washed with $\mathrm{HCl}(3 \times 10 \mathrm{~mL})$. A precipitate formed which was filtered and washed thrice with hexane $(3 \times 10 \mathrm{~mL})$, after which it 
was dried under vacuum to afford the cinnamic acids $\mathbf{2 a -}$ c and $\mathbf{2 h}$-i (Figure 1), whose ${ }^{1} \mathrm{H}$ NMR was consistent with that in the literature [30-34]. The cinnamic acids $\mathbf{2} \mathbf{d}-\mathbf{g}$ and $\mathbf{2 j}$ were purchased from Sigma Aldrich via Capital Laboratories, South Africa.

$2^{\prime}$-Fluorocinnamic acid $(2 a)$ yield $91 \%$; mp $175-176^{\circ} \mathrm{C}$ (lit. $\left.176.5-177^{\circ} \mathrm{C}[30]\right) ; 3^{\prime}$-fluorocinnamic acid (2b) yield $84 \%, \mathrm{mp}$ $166-167^{\circ} \mathrm{C}$ (lit. $167^{\circ} \mathrm{C}[35]$ ); $4^{\prime}$-fluorocinnamic acid (2c) yield $88 \%, \mathrm{mp} 206-208^{\circ} \mathrm{C}$ (lit. $208^{\circ} \mathrm{C}[32]$ ); $4^{\prime}$-methoxycinnamic acid ( 2 h) yield $92 \%, \mathrm{mp} 172-173^{\circ} \mathrm{C}$ (lit. $\left.173-175^{\circ} \mathrm{C}[33]\right) ; 3^{\prime}, 4^{\prime}-$ dimethoxycinnamic acid (2i) yield $83 \%$, mp $181-183^{\circ} \mathrm{C}$ (lit. $\left.182-184^{\circ} \mathrm{C}[36]\right)$.

2.3. Typical Procedure for the Synthesis of Substituted 2(Cinnamoyloxy) Acetophenones (3a-j). $\mathrm{POCl}_{3}(15.6 \mathrm{mmol}$, $2.39 \mathrm{~g}$ ) was added to a solution of the appropriate 2hydroxyacetophenone $(12.0 \mathrm{mmol})$ and the appropriate cinnamic acid $(15.6 \mathrm{mmol})$ in dry pyridine $(10 \mathrm{~mL})$. The solution was stirred at $60-70^{\circ} \mathrm{C}$ for $3 \mathrm{~h}$ and then poured into ice and water $(20 \mathrm{~mL})$, and the reaction mixture acidified with $\mathrm{HCl}$ ( $\mathrm{pH} 3-4)$. The obtained solid was removed by filtration, dissolved in EtOAc $(100 \mathrm{~mL})$, and purified by silica gel column chromatography using a 7:3 mixture of EtOAc: $n$-hexane as the eluent. The solvent was evaporated to dryness, and the residue recrystallized from $\mathrm{EtOH}$, resulting in compounds $3 \mathbf{a}-\mathbf{j}$.

2'-(2-Fluorocinnamoyloxy) Acetophenone (3a). Brown solid residue $\left(90 \%\right.$ yield); $\mathrm{mp} 68-70^{\circ} \mathrm{C}$; IR $(\mathrm{KBr}) v_{\max }: 1682(\mathrm{br}$ $\mathrm{C}=\mathrm{O}), 1627(\mathrm{C}=\mathrm{C}), 1612$ (aromatic C-C), 1483, 1456, 1284 (CF), $1227 \mathrm{~cm}^{-1} ;{ }^{1} \mathrm{H}$ NMR $\left(\mathrm{CDCl}_{3}, 400 \mathrm{MHz}\right) \delta 8.00(1 \mathrm{H}, \mathrm{d}, J$ $=16.2 \mathrm{~Hz}, \mathrm{H}-\beta), 7.85\left(1 \mathrm{H}, \mathrm{dd}, J=7.9,1.6 \mathrm{~Hz}, \mathrm{H}-6^{\prime}\right), 7.59(1 \mathrm{H}$, td, $\left.J=7.9,1.7 \mathrm{~Hz}, \mathrm{H}-6^{\prime \prime}\right), 7.54\left(1 \mathrm{H}, \mathrm{td}, J=7.6,1.6 \mathrm{~Hz}, \mathrm{H}-4^{\prime}\right)$, 7.39-7.40 (1H, m, H-4 $\left.{ }^{\prime \prime}\right), 7.33\left(1 \mathrm{H}, \mathrm{td}, J=7.6,0.8 \mathrm{~Hz}, \mathrm{H}-5^{\prime}\right), 7.19$ $\left(1 \mathrm{H}, \mathrm{dd}, J=8.0,0.8 \mathrm{~Hz}, \mathrm{H}-3^{\prime}\right), 7.18\left(1 \mathrm{H}, \mathrm{t}, J=7.5 \mathrm{~Hz}, \mathrm{H}-5^{\prime \prime}\right), 7.11$ $\left(1 \mathrm{H}, \mathrm{dd}, J=10.3,8.8 \mathrm{~Hz}, \mathrm{H}-3^{\prime \prime}\right), 6.76(1 \mathrm{H}, \mathrm{d}, J=16.2 \mathrm{~Hz}, \mathrm{H}-\alpha)$, $2.55\left(3 \mathrm{H}, \mathrm{s}, \mathrm{CH}_{3}-2\right) ;{ }^{13} \mathrm{C} \mathrm{NMR}\left(\mathrm{CDCl}_{3}, 100 \mathrm{MHz}\right) \delta 197.7(\mathrm{C}-$ 1), $165.1(\mathrm{C}=\mathrm{O}), 161.8\left(\mathrm{~d}, J_{\mathrm{CF}}=252.6 \mathrm{~Hz}, \mathrm{C}-2^{\prime \prime}\right), 149.1\left(\mathrm{C}-2^{\prime}\right)$, $140.0(\mathrm{~d}, J=2.7 \mathrm{~Hz}, \mathrm{C}-\beta), 133.4\left(\mathrm{C}-4^{\prime}\right), 132.2(\mathrm{~d}, J=14.2 \mathrm{~Hz}, \mathrm{C}-$ $\left.4^{\prime \prime}\right), 131.3\left(\mathrm{C}-1^{\prime \prime}\right), 130.2\left(\mathrm{C}-6^{\prime}\right), 129.4\left(\mathrm{~d}, J=2.7 \mathrm{~Hz}, \mathrm{C}-6^{\prime \prime}\right), 126.1$ $\left(\mathrm{C}-5^{\prime}\right), 124.6\left(\mathrm{~d}, J=3.6 \mathrm{~Hz}, \mathrm{C}-5^{\prime \prime}\right), 123.8\left(\mathrm{C}-3^{\prime}\right), 122.2(\mathrm{~d}, J=$ $\left.11.6 \mathrm{~Hz}, \mathrm{C}-1^{\prime \prime}\right), 119.4(\mathrm{~d}, J=6.9 \mathrm{~Hz}, \mathrm{C}-\alpha), 116.3(\mathrm{~d}, J=21.7 \mathrm{~Hz}$, C-3" $), 29.8(\mathrm{C}-2) ;{ }^{19} \mathrm{~F}$ NMR $\left(\mathrm{CDCl}_{3}, 376.5 \mathrm{MHz}\right) \delta-113.57$; EIMS (probe) $70 \mathrm{eV}, \mathrm{m} / z$ (rel. int.): $284 \mathrm{M}^{+}$(3), 149 (100), 121 (63), 101 (65), 75 (15); calculated molecular mass: 284.28.

$2^{\prime}$-(3-Fluorocinnamoyloxy) Acetophenone (3b). Brown solid residue (68\% yield): $\mathrm{mp} 55-56^{\circ} \mathrm{C}$; $\mathrm{IR}(\mathrm{KBr}) v_{\max }$ : 1733 and 1673 $(\mathrm{C}=\mathrm{O}), 1637(\mathrm{C}=\mathrm{C}), 1444,1136(\mathrm{C}-\mathrm{F}), 1073 \mathrm{~cm}^{-1} ;{ }^{1} \mathrm{H}$ NMR $\left(\mathrm{CDCl}_{3}, 400 \mathrm{MHz}\right) \delta 7.83\left(1 \mathrm{H}, \mathrm{dd}, J=7.6,1.6 \mathrm{~Hz}, \mathrm{H}-6^{\prime}\right), 7.82$ $(1 \mathrm{H}, \mathrm{d}, J=16.0 \mathrm{~Hz}, \mathrm{H}-\beta), 7.55\left(1 \mathrm{H}, \mathrm{td}, J=7.8,1.6 \mathrm{~Hz}, \mathrm{H}-4^{\prime}\right)$, $7.35-7.37\left(2 \mathrm{H}, \mathrm{m}, \mathrm{H}-5^{\prime}, \mathrm{H}-6^{\prime \prime}\right), 7.33\left(1 \mathrm{H}, \mathrm{td}, J=7.7,0.8, \mathrm{H}-5^{\prime \prime}\right)$, $7.27\left(1 \mathrm{H}, \mathrm{d}, J=9.6 \mathrm{~Hz}, \mathrm{H}-2^{\prime \prime}\right), 7.17(1 \mathrm{H}, \mathrm{dd}, J=8.0,0.7 \mathrm{~Hz}, \mathrm{H}-$ $\left.3^{\prime}\right), 7.10\left(1 \mathrm{H}, \mathrm{tt}, J=8.2,2.0 \mathrm{~Hz}, \mathrm{H}-4^{\prime \prime}\right), 6.55(1 \mathrm{H}, \mathrm{d}, J=16.0 \mathrm{~Hz}$, $\mathrm{H}-\alpha), 2.55\left(3 \mathrm{H}, \mathrm{s}, \mathrm{CH}_{3}-2\right) ;{ }^{13} \mathrm{C} \mathrm{NMR}\left(\mathrm{CDCl}_{3}, 100 \mathrm{MHz}\right) \delta$ 197.7 (C-1), $164.9(\mathrm{C}=\mathrm{O}), 163.0\left(\mathrm{~d}, J_{\mathrm{CF}}=245.6 \mathrm{~Hz}, \mathrm{C}-3^{\prime \prime}\right), 149.0$ $\left(\mathrm{C}-2^{\prime}\right), 145.8(\mathrm{~d}, J=2.7 \mathrm{~Hz}, \mathrm{C}-\beta), 136.3\left(\mathrm{~d}, J=7.9 \mathrm{~Hz}, \mathrm{C}-1^{\prime \prime}\right)$, $133.4\left(\mathrm{C}-4^{\prime}\right), 131.2\left(\mathrm{C}-1^{\prime}\right), 130.6\left(\mathrm{~d}, J=8.0 \mathrm{~Hz}, \mathrm{C}-5^{\prime \prime}\right), 130.2(\mathrm{C}-$ $\left.6^{\prime}\right), 126.2\left(\mathrm{C}-5^{\prime}\right), 124.4\left(\mathrm{~d}, J=2.9 \mathrm{~Hz}, \mathrm{C}-6^{\prime \prime}\right), 123.8\left(\mathrm{C}-3^{\prime}\right), 118.3$
$(\mathrm{C}-\alpha), 117.7\left(\mathrm{~d}, J=21.3 \mathrm{~Hz}, \mathrm{C}-4^{\prime \prime}\right), 114.6\left(\mathrm{~d}, J=21.9 \mathrm{~Hz}, \mathrm{C}-2^{\prime \prime}\right)$, $30.0(\mathrm{C}-2) ;{ }^{19} \mathrm{~F}$ NMR $\left(\mathrm{CDCl}_{3}, 376.5 \mathrm{MHz}\right) \delta-112.27$; EIMS (probe) $70 \mathrm{eV}, \mathrm{m} / z$ (rel. int.): $284 \mathrm{M}^{+}$(3), 149 (100), 121 (60), 101 (55), 75 (11); calculated molecular mass: 284.28.

$2^{\prime}$-(4-Fluorocinnamoyloxy) Acetophenone (3c). Cream solid residue $\left(72 \%\right.$ yield); $\mathrm{mp} 80-82^{\circ} \mathrm{C}$; $\mathrm{IR}(\mathrm{KBr}) v_{\max }: 1729(\mathrm{C}=\mathrm{O})$, $1670(\mathrm{C}=\mathrm{O}), 1624(\mathrm{C}=\mathrm{C}), 1590,1446,1221(\mathrm{C}-\mathrm{F}), 1202,1159$, $1050 \mathrm{~cm}^{-1} ;{ }^{1} \mathrm{H}$ NMR $\left(\mathrm{CDCl}_{3}, 400 \mathrm{MHz}\right) \delta 7.84(1 \mathrm{H}, \mathrm{d}, J=$ $16.0 \mathrm{~Hz}, \mathrm{H}-\beta), 7.81\left(1 \mathrm{H}, \mathrm{dd}, J=8.0,1.6 \mathrm{~Hz}, \mathrm{H}-6^{\prime}\right), 7.58(2 \mathrm{H}, \mathrm{dd}, J$ $\left.=8.6,5.4 \mathrm{~Hz}, \mathrm{H}-2^{\prime \prime} / 6^{\prime \prime}\right), 7.53\left(1 \mathrm{H}, \mathrm{dd}, J=8.0,1.5 \mathrm{~Hz}, \mathrm{H}-4^{\prime}\right), 7.33$ $\left(1 \mathrm{H}, \mathrm{td}, J=8.1,0.7 \mathrm{~Hz}, \mathrm{H}-5^{\prime}\right), 7.17\left(1 \mathrm{H}, \mathrm{dd}, J=8.1,0.7 \mathrm{~Hz}, \mathrm{H}-3^{\prime}\right)$, $7.09\left(2 \mathrm{H}, \mathrm{t}, J=8.6 \mathrm{~Hz}, \mathrm{H}-3^{\prime \prime} / 5^{\prime \prime}\right), 6.58(1 \mathrm{H}, \mathrm{d}, J=16.0 \mathrm{~Hz}, \mathrm{H}-\alpha)$, $2.54\left(\mathrm{~s}, 3 \mathrm{H}, \mathrm{CH}_{3}-2\right) ;{ }^{13} \mathrm{C}$ NMR $\left(\mathrm{CDCl}_{3}, 100 \mathrm{MHz}\right) \delta 197.8(\mathrm{C}-$ 1), $165.1(\mathrm{C}=\mathrm{O}), 164.3\left(\mathrm{~d}, J_{\mathrm{CF}}=250.7 \mathrm{~Hz}, \mathrm{C}-4^{\prime \prime}\right), 149.1\left(\mathrm{C}-2^{\prime}\right)$, $146.0(\mathrm{C}-\beta), 133.4\left(\mathrm{C}-4^{\prime}\right), 131.3\left(\mathrm{C}-1^{\prime}\right), 130.4(\mathrm{~d}, J=8.4 \mathrm{~Hz}, \mathrm{C}-$ $\left.2^{\prime \prime} / 6^{\prime \prime}\right), 130.32\left(\mathrm{~d}, J=3.6 \mathrm{~Hz}, \mathrm{C}-1^{\prime \prime}\right), 130.2\left(\mathrm{C}-6^{\prime}\right), 126.1\left(\mathrm{C}-5^{\prime}\right)$, $123.8\left(\mathrm{C}-3^{\prime}\right), 116.6(\mathrm{~d}, J=2.4 \mathrm{~Hz}, \mathrm{C}-\alpha), 116.2(\mathrm{~d}, J=21.9 \mathrm{~Hz}, \mathrm{C}-$ $\left.3^{\prime \prime} / 5^{\prime \prime}\right), 29.7(\mathrm{C}-2) ;{ }^{19} \mathrm{~F} \mathrm{NMR}\left(\mathrm{CDCl}_{3}, 376.5 \mathrm{MHz}\right) \delta-108.54$; EIMS (probe) $70 \mathrm{eV},\left(\mathrm{m} / z\right.$, rel. int.) $284 \mathrm{M}^{+}(21), 149$ (100), 121 (25), 101 (20); calculated molecular mass: 284.28 .

$2^{\prime}$-(3,5-Difluorocinnamoyloxy) Acetophenone (3d). Brown solid residue (70\% yield); mp 58-59 ${ }^{\circ} \mathrm{C}$; IR $(\mathrm{KBr}) v_{\max }: 1729$ $(\mathrm{C}=\mathrm{O}), 1682(\mathrm{C}=\mathrm{O}), 1249(\mathrm{C}-\mathrm{F}), 1201,1122 \mathrm{~cm}^{-1} ;{ }^{1} \mathrm{H}$ NMR $\left(\mathrm{CDCl}_{3}, 400 \mathrm{MHz}\right) \delta 7.82\left(1 \mathrm{H}, \mathrm{dd}, J=7.9,1.0 \mathrm{~Hz}, \mathrm{H}-6^{\prime}\right), 7.75$ $(1 \mathrm{H}, \mathrm{d}, J=16.0 \mathrm{~Hz}, \mathrm{H}-\beta), 7.55\left(1 \mathrm{H}, \mathrm{td}, J=7.6,1.1 \mathrm{~Hz}, \mathrm{H}-4^{\prime}\right)$, $7.34\left(1 \mathrm{H}, \mathrm{t}, J=7.6 \mathrm{~Hz}, \mathrm{H}-5^{\prime}\right), 7.16(1 \mathrm{H}, \mathrm{dd}, J=7.9,0.8 \mathrm{~Hz}, \mathrm{H}-$ $\left.3^{\prime}\right), 7.08-7.10\left(2 \mathrm{H}, \mathrm{m}, \mathrm{H}-2^{\prime \prime} / 6^{\prime \prime}\right), 6.85(1 \mathrm{H}, \mathrm{tt}, J=8.7,2.3 \mathrm{~Hz}$, $\left.\mathrm{H}-4^{\prime \prime}\right), 6.64(1 \mathrm{H}, \mathrm{d}, J=16.0 \mathrm{~Hz}, \mathrm{H}-\alpha), 2.54\left(3 \mathrm{H}, \mathrm{s}, \mathrm{CH}_{3}-2\right)$; ${ }^{13} \mathrm{C} \mathrm{NMR}\left(\mathrm{CDCl}_{3}, 100 \mathrm{MHz}\right) \delta 197.6(\mathrm{C}-1), 164.6(\mathrm{C}=\mathrm{O}), 163.2$ $\left(\mathrm{dd}, J_{\mathrm{CF}}=248.3,12.8 \mathrm{~Hz}, \mathrm{C}-3^{\prime \prime} / 5^{\prime \prime}\right), 148.9\left(\mathrm{C}-2^{\prime}\right), 144.5(\mathrm{t}, J=$ $2.8 \mathrm{~Hz}, \mathrm{C}-\beta), 137.3$ (d, $\left.J=9.5 \mathrm{~Hz}, \mathrm{C}-1^{\prime \prime}\right), 133.5\left(\mathrm{C}-4^{\prime}\right), 131.0$ (C$\left.1^{\prime}\right), 130.3\left(\mathrm{C}-6^{\prime}\right), 126.3\left(\mathrm{C}-5^{\prime}\right), 123.7\left(\mathrm{C}-3^{\prime}\right), 119.7(\mathrm{C}-\alpha), 111.0$ (dd, $\left.J=18.8,7.2 \mathrm{~Hz}, \mathrm{C}-2^{\prime \prime} / 6^{\prime \prime}\right), 105.9\left(\mathrm{t}, J=25.4 \mathrm{~Hz}, \mathrm{C}-4^{\prime \prime}\right)$, 29.5 (C-2); ${ }^{19} \mathrm{~F} \mathrm{NMR}\left(\mathrm{CDCl}_{3}, 376.5 \mathrm{MHz}\right) \delta-108.75$; EIMS (probe) $70 \mathrm{eV},\left(\mathrm{m} / z\right.$, rel. int.): $302 \mathrm{M}^{+}$(3), 167 (100), 139 (79), 119 (60); calculated molecular mass: 302.27.

$4^{\prime}$-Fluoro-2' -(4-fluorocinnamoyloxy) Acetophenone (3e). Offwhite solid residue (68\% yield); $\mathrm{mp} 60-62^{\circ} \mathrm{C}$; IR $(\mathrm{KBr}) v_{\max }$ : $1724(\mathrm{C}=\mathrm{O}), 1679(\mathrm{C}=\mathrm{O}), 1361(\mathrm{C}-\mathrm{O}), 1225(\mathrm{C}-\mathrm{F}), 1143 \mathrm{~cm}^{-1}$; ${ }^{1} \mathrm{H} \mathrm{NMR}\left(\mathrm{CDCl}_{3}, 400 \mathrm{MHz}\right) \delta 7.87(1 \mathrm{H}, \mathrm{dd}, J=8.8,6.3 \mathrm{~Hz}$, H-6 $\left.6^{\prime}\right), 7.84(1 \mathrm{H}, \mathrm{d}, J=16.0 \mathrm{~Hz}, \mathrm{H}-\beta), 7.58(2 \mathrm{H}, \mathrm{dd}, J=5.4$, $\left.2.0 \mathrm{~Hz}, \mathrm{H}-2^{\prime \prime} / 6^{\prime \prime}\right), 7.10\left(2 \mathrm{H}, \mathrm{dd}, J=8.7,2.5 \mathrm{~Hz}, \mathrm{H}-3^{\prime \prime} / 5^{\prime \prime}\right), 7.03$ $\left(1 \mathrm{H}, \mathrm{td}, J=8.8,2.5 \mathrm{~Hz}, \mathrm{H}-5^{\prime}\right), 6.92\left(\mathrm{dd}, J=8.9,2.5 \mathrm{~Hz}, \mathrm{H}-3^{\prime}\right)$, $6.56(1 \mathrm{H}, \mathrm{d}, J=16.0 \mathrm{~Hz}, \mathrm{H}-\alpha), 2.53\left(3 \mathrm{H}, \mathrm{s}, \mathrm{CH}_{3}-2\right) ;{ }^{13} \mathrm{C} \mathrm{NMR}$ $\left(\mathrm{CDCl}_{3}, 100 \mathrm{MHz}\right) \delta 196.1(\mathrm{C}-1), 165.1(\mathrm{C}=\mathrm{O}), 165.0\left(\mathrm{~d}, J_{\mathrm{CF}}=\right.$ $\left.254.1 \mathrm{~Hz}, \mathrm{C}-4^{\prime}\right), 164.4\left(\mathrm{~d}, J_{\mathrm{CF}}=251.0 \mathrm{~Hz}, \mathrm{C}-4^{\prime \prime}\right), 151.0(\mathrm{~d}, J=$ $\left.11.2 \mathrm{~Hz}, \mathrm{C}-2^{\prime}\right), 146.6(\mathrm{C}-\beta), 132.2\left(\mathrm{~d}, J=10.1 \mathrm{~Hz}, \mathrm{C}-6^{\prime}\right), 130.5$ $\left(\mathrm{d}, J=8.5 \mathrm{~Hz}, \mathrm{C}-2^{\prime \prime} / 6^{\prime \prime}\right), 130.2\left(\mathrm{~d}, J=3.0 \mathrm{~Hz}, \mathrm{C}-1^{\prime \prime}\right), 127.6(\mathrm{~d}$, $\left.J=3.5 \mathrm{~Hz}, \mathrm{C}-1^{\prime}\right), 116.3\left(\mathrm{~d}, J=21.9 \mathrm{~Hz}, \mathrm{C}-3^{\prime \prime} / 5^{\prime \prime}\right), 116.1(\mathrm{~d}, J=$ $2.2 \mathrm{~Hz}, \mathrm{C}-\alpha), 113.3\left(\mathrm{~d}, J=21.2 \mathrm{~Hz}, \mathrm{C}-5^{\prime}\right), 111.7(\mathrm{~d}, J=24.0 \mathrm{~Hz}$, C-3'), $29.7(\mathrm{C}-2) ;{ }^{19} \mathrm{~F} \mathrm{NMR}\left(\mathrm{CDCl}_{3}, 376.5 \mathrm{MHz}\right) \delta-103.81$, -103.17; EIMS (probe) $70 \mathrm{eV}\left(\mathrm{m} / z\right.$, rel. int.) $302 \mathrm{M}^{+}$(3), 149 (100), 121 (92), 101 (75); calculated molecular mass: 302.27.

4'-Fluoro-2'-cinnamoyloxy Acetophenone (3f). Brown solid residue ( $86 \%$ yield); $\mathrm{mp} 98-100^{\circ} \mathrm{C} ; \mathrm{IR}(\mathrm{KBr}) v_{\max }: 1730(\mathrm{C}=\mathrm{O})$, 
$1678(\mathrm{C}=\mathrm{O}), 1634,1598,1247(\mathrm{C}-\mathrm{F}), 1100,886 \mathrm{~cm}^{-1} ;{ }^{1} \mathrm{H}$ NMR $\left(\mathrm{CDCl}_{3}, 400 \mathrm{MHz}\right) \delta 7.88(1 \mathrm{H}, \mathrm{d}, J=15.9 \mathrm{~Hz}, \mathrm{H}-\beta), 7.86(1 \mathrm{H}$, $\left.\mathrm{dd}, J=8.6,5.4 \mathrm{~Hz}, \mathrm{H}-6^{\prime}\right), 7.58(2 \mathrm{H}, \mathrm{dd}, J=7.5,1.9 \mathrm{~Hz}, \mathrm{H}-$ $\left.2^{\prime \prime} / 6^{\prime \prime}\right), 7.43-7.45\left(3 \mathrm{H}, \mathrm{m}, \mathrm{H}-3^{\prime \prime} / 4^{\prime \prime} / 5^{\prime \prime}\right), 7.03$ (1H, ddd, $J=8.6$, $\left.7.9,2.5 \mathrm{~Hz}, \mathrm{H}-5^{\prime}\right), 6.94\left(1 \mathrm{H}, \mathrm{dd}, J=8.9,2.5 \mathrm{~Hz}, \mathrm{H}-3^{\prime}\right), 6.63(1 \mathrm{H}$, d, $J=15.9 \mathrm{~Hz}, \mathrm{H}-\alpha), 2.53\left(3 \mathrm{H}, \mathrm{s}, \mathrm{CH}_{3}-2\right) ;{ }^{13} \mathrm{C} \mathrm{NMR}\left(\mathrm{CDCl}_{3}\right.$, $100 \mathrm{MHz}) \delta 196.1(\mathrm{C}-1), 166.4\left(\mathrm{~d}, J_{\mathrm{CF}}=255.8 \mathrm{~Hz}, \mathrm{C}-4^{\prime}\right), 164.8$ $(\mathrm{C}=\mathrm{O}), 151.0\left(\mathrm{C}-2^{\prime}\right), 145.4(\mathrm{C}-\beta), 133.9\left(\mathrm{C}-1^{\prime \prime}\right), 132.3(\mathrm{~d}, J=$ 10.2 Hz, C- $\left.6^{\prime}\right), 131.1\left(\mathrm{C}-4^{\prime \prime}\right), 129.0\left(\mathrm{C}-2^{\prime \prime} / 6^{\prime \prime}\right), 128.5\left(\mathrm{C}-3^{\prime \prime} / 5^{\prime \prime}\right)$, $127.0\left(\mathrm{C}-1^{\prime}\right), 116.3(\mathrm{C}-\alpha), 113.4\left(\mathrm{~d}, J=21.1 \mathrm{~Hz}, \mathrm{C}-3^{\prime}\right), 111.7$ (d, $\left.J=24.1 \mathrm{~Hz}, \mathrm{C}-5^{\prime}\right), 29.8(\mathrm{C}-2) ;{ }^{19} \mathrm{~F} \mathrm{NMR}\left(\mathrm{CDCl}_{3}, 376.5 \mathrm{MHz}\right)$ $\delta$-103.91; EIMS (probe) $70 \mathrm{eV}\left(\mathrm{m} / z\right.$, rel. int.) $284 \mathrm{M}^{+}$(3), 131 (100), 103 (71), 77 (39), 51 (11); calculated molecular mass: 284.28.

$5^{\prime}$-Fluoro-2'-cinnamoyloxy Acetophenone (3g). Brown solid residue (90\% yield); $\mathrm{mp} 81-83^{\circ} \mathrm{C}$; IR $(\mathrm{KBr}) v_{\max }: 1731(\mathrm{C}=\mathrm{O})$, $1681(\mathrm{C}=\mathrm{O}), 1632,1581,1131(\mathrm{C}-\mathrm{F}), 983 \mathrm{~cm}^{-1} ;{ }^{1} \mathrm{H}$ NMR $\left(\mathrm{CDCl}_{3}, 400 \mathrm{MHz}\right) \delta 7.88(1 \mathrm{H}, \mathrm{d}, J=15.9 \mathrm{~Hz}, \mathrm{H}-\beta), 7.58-7.59$ $\left(2 \mathrm{H}, \mathrm{m}, \mathrm{H}-2^{\prime \prime} / 6^{\prime \prime}\right), 7.49\left(1 \mathrm{H}, \mathrm{dd}, J=8.7,3.0 \mathrm{~Hz}, \mathrm{H}-3^{\prime}\right), 7.39-$ $7.41\left(3 \mathrm{H}, \mathrm{m}, \mathrm{H}-3^{\prime \prime} / 4^{\prime \prime} / 5^{\prime \prime}\right), 7.23\left(1 \mathrm{H}, \mathrm{dd}, J=7.8,3.0 \mathrm{~Hz}, \mathrm{H}-4^{\prime}\right)$, $7.15\left(1 \mathrm{H}, \mathrm{dd}, J=8.7,4.7 \mathrm{~Hz}, \mathrm{H}-6^{\prime}\right), 6.64(1 \mathrm{H}, \mathrm{d}, J=15.9 \mathrm{~Hz}$, $\mathrm{H}-\alpha), 2.53\left(3 \mathrm{H}, \mathrm{s}, \mathrm{CH}_{3}-2\right) ;{ }^{13} \mathrm{C} \mathrm{NMR}\left(\mathrm{CDCl}_{3}, 100 \mathrm{MHz}\right) \delta$ $196.4(\mathrm{C}-1), 165.2(\mathrm{C}=\mathrm{O}), 159.9\left(\mathrm{~d}, J_{\mathrm{CF}}=245.1 \mathrm{~Hz}, \mathrm{C}-5^{\prime}\right), 147.8$ $\left(\mathrm{C}-2^{\prime}\right), 145.0(\mathrm{C}-\beta), 133.9\left(\mathrm{C}-1^{\prime \prime}\right), 132.6\left(\mathrm{~d}, J=6.1 \mathrm{~Hz}, \mathrm{C}-1^{\prime}\right)$, $131.0\left(\mathrm{C}-4^{\prime \prime}\right), 129.0\left(\mathrm{C}-3^{\prime \prime} / 5^{\prime \prime}\right), 128.5\left(\mathrm{C}-2^{\prime \prime} / 6^{\prime \prime}\right), 125.4(\mathrm{~d}, J$ $\left.=8.0 \mathrm{~Hz}, \mathrm{C}-3^{\prime}\right), 120.1\left(\mathrm{~d}, J=23.3 \mathrm{~Hz}, \mathrm{C}-6^{\prime}\right), 116.5(\mathrm{~d}, J=$ $\left.20.5 \mathrm{~Hz}, \mathrm{C}-4^{\prime}\right), 116.6(\mathrm{C}-\alpha), 29.8(\mathrm{C}-2) ;{ }^{19} \mathrm{~F}$ NMR $\left(\mathrm{CDCl}_{3}\right.$, $376.5 \mathrm{MHz}) \delta-115.35$; EIMS (probe) $70 \mathrm{eV}(\mathrm{m} / z$, rel. int.) $284 \mathrm{M}^{+}$(30), 266 (8), 145 (25), 131 (100), 103 (44), 77 (21); calculated molecular mass: 284.28 .

2'-(4-Methoxycinnamoyloxy) Acetophenone (3h). Off-white solid residue ( $91 \%$ yield); $\mathrm{mp} 97-99^{\circ} \mathrm{C}$ (lit. 103-105 $\mathrm{C}$ [20]); IR $(\mathrm{KBr}) v_{\max }: 1711(\mathrm{C}=\mathrm{O}), 1680(\mathrm{C}=\mathrm{O}), 1600(\mathrm{C}=\mathrm{C}), 1509,1581$, $1246,1189 \mathrm{~cm}^{-1} ;{ }^{1} \mathrm{H}$ NMR $\left(\mathrm{CDCl}_{3}, 400 \mathrm{MHz}\right) \delta 7.83(1 \mathrm{H}, \mathrm{d}, J$ $=15.9 \mathrm{~Hz}, \mathrm{H}-\beta), 7.80\left(1 \mathrm{H}, \mathrm{dd}, J=8.0,1.6 \mathrm{~Hz}, \mathrm{H}-6^{\prime}\right), 7.53(2 \mathrm{H}$, d, $\left.J=8.7 \mathrm{~Hz}, \mathrm{H}-2^{\prime \prime} / 6^{\prime \prime}\right), 7.51\left(1 \mathrm{H}, \mathrm{td}, J=7.6,1.6 \mathrm{~Hz}, \mathrm{H}-4^{\prime}\right), 7.31$ $\left(1 \mathrm{H}, \mathrm{td}, J=8.0,0.8 \mathrm{~Hz}, \mathrm{H}-5^{\prime}\right), 7.17\left(1 \mathrm{H}, \mathrm{d}, J=8.0 \mathrm{~Hz}, \mathrm{H}-3^{\prime}\right)$, $6.91\left(\mathrm{dd}, J=8.7,2.6 \mathrm{~Hz}, \mathrm{H}-3^{\prime \prime} / 5^{\prime \prime}\right), 6.52(1 \mathrm{H}, \mathrm{d}, J=15.9 \mathrm{~Hz}$, $\mathrm{H}-\alpha), 3.84\left(3 \mathrm{H}, \mathrm{s}, \mathrm{OCH}_{3}\right), 2.54\left(3 \mathrm{H}, \mathrm{s}, \mathrm{CH}_{3}-2\right) ;{ }^{13} \mathrm{C} \mathrm{NMR}$ $\left(\mathrm{CDCl}_{3}, 100 \mathrm{MHz}\right) \delta 197.9(\mathrm{C}-1), 165.5(\mathrm{C}=\mathrm{O}), 161.9\left(\mathrm{C}-4^{\prime \prime}\right)$, $149.3\left(\mathrm{C}-2^{\prime}\right), 147.2(\mathrm{C}-\beta), 133.3\left(\mathrm{C}-4^{\prime}\right), 131.5\left(\mathrm{C}-1^{\prime}\right), 130.2(\mathrm{C}-$ $\left.2^{\prime \prime} / 6^{\prime \prime}\right), 130.0\left(\mathrm{C}-6^{\prime}\right), 126.8\left(\mathrm{C}-1^{\prime \prime}\right), 126.0\left(\mathrm{C}-5^{\prime}\right), 123.8\left(\mathrm{C}-3^{\prime}\right)$, $114.5\left(\mathrm{C}-3^{\prime \prime} / 5^{\prime \prime}\right), 114.1(\mathrm{C}-\alpha), 55.4\left(\mathrm{OCH}_{3}\right), 29.9(\mathrm{C}-2)$; EIMS (probe) $70 \mathrm{eV}\left(\mathrm{m} / z\right.$, rel. int.) $296 \mathrm{M}^{+}(7), 161(100), 133$ (49), 118 (16), 90 (15), 77 (16); calculated molecular mass: 296.10.

2'-(3,4-Dimethoxycinnamoyloxy) Acetophenone (3i). Offwhite solid residue $\left(56 \%\right.$ yield); mp $99-101^{\circ} \mathrm{C}$ (lit. $97-99^{\circ} \mathrm{C}$ [37]); IR (KBr) $v_{\max }: 1728(\mathrm{C}=\mathrm{O}), 1683(\mathrm{C}=\mathrm{O}), 1633(\mathrm{C}=\mathrm{C})$, $1515,1254 \mathrm{~cm}^{-1}$; ${ }^{1} \mathrm{H}$ NMR $\left(\mathrm{CDCl}_{3}, 400 \mathrm{MHz}\right) \delta 7.82(1 \mathrm{H}, \mathrm{d}, J$ $=15.9 \mathrm{~Hz}, \mathrm{H}-\beta), 7.81\left(1 \mathrm{H}, \mathrm{dd}, J=7.8,1.7 \mathrm{~Hz}, \mathrm{H}-6^{\prime}\right), 7.54(\mathrm{td}, J=$ 7.9, $\left.1.6 \mathrm{~Hz}, \mathrm{H}-4^{\prime}\right), 7.31\left(1 \mathrm{H}, \mathrm{td}, J=7.6,0.9 \mathrm{~Hz}, \mathrm{H}-5^{\prime}\right), 7.17(1 \mathrm{H}$, d, $\left.J=8.0 \mathrm{~Hz}, \mathrm{H}-3^{\prime}\right), 7.16\left(1 \mathrm{H}, \mathrm{dd}, J=8.2,1.9 \mathrm{~Hz}, \mathrm{H}-6^{\prime \prime}\right), 7.10$ $\left(1 \mathrm{H}, \mathrm{d}, J=1.9 \mathrm{~Hz}, \mathrm{H}-2^{\prime \prime}\right), 6.87\left(1 \mathrm{H}, \mathrm{d}, J=8.2 \mathrm{~Hz}, \mathrm{H}-5^{\prime \prime}\right), 6.52$ $(1 \mathrm{H}, \mathrm{d}, J=15.9 \mathrm{~Hz}, \mathrm{H}-\alpha), 3.91\left(6 \mathrm{H}, \mathrm{s}, 2 \mathrm{x} \mathrm{OCH}_{3}\right), 2.55(3 \mathrm{H}$, $\left.\mathrm{s}, \mathrm{CH}_{3}-2\right) ;{ }^{13} \mathrm{C} \mathrm{NMR}\left(\mathrm{CDCl}_{3}, 100 \mathrm{MHz}\right) \delta 197.9(\mathrm{C}-1), 165.5$ $(\mathrm{C}=\mathrm{O}), 151.7\left(\mathrm{C}-2^{\prime}\right), 149.3\left(\mathrm{C}-4^{\prime \prime}\right), 149.2\left(\mathrm{C}-3^{\prime \prime}\right), 147.4(\mathrm{C}-\beta)$,
$133.3\left(\mathrm{C}-4^{\prime}\right), 131.5\left(\mathrm{C}-1^{\prime}\right), 130.1\left(\mathrm{C}-6^{\prime}\right), 127.0\left(\mathrm{C}-1^{\prime \prime}\right), 126.0$ $\left(\mathrm{C}-5^{\prime}\right), 123.8\left(\mathrm{C}-3^{\prime}\right), 123.3\left(\mathrm{C}-6^{\prime \prime}\right), 114.4(\mathrm{C}-\alpha), 111.1\left(\mathrm{C}-5^{\prime \prime}\right)$, $109.8\left(\mathrm{C}-2^{\prime \prime}\right), 55.9\left(\mathrm{OCH}_{3}\right), 56.0\left(\mathrm{OCH}_{3}\right), 29.9$ (C-2); EIMS (probe) $70 \mathrm{eV}\left(\mathrm{m} / \mathrm{z}\right.$, rel. int.) $326 \mathrm{M}^{+}(20), 191$ (100), 163 (36), 148 (19), 77 (22); calculated molecular mass: 326.10.

$2^{\prime}$-(3,4-Methylenedioxycinnamoyloxy) Acetophenone (3j). Off-white solid residue (59\% yield), mp 99-100 $\mathrm{C}$, IR (KBr) $v_{\max }: 1715(\mathrm{C}=\mathrm{O}), 1679(\mathrm{C}=\mathrm{O}), 1600(\mathrm{C}=\mathrm{C}), 1449,1202(\mathrm{C}-\mathrm{F})$, $925 \mathrm{~cm}^{-1} ;{ }^{1} \mathrm{H} \mathrm{NMR}\left(\mathrm{CDCl}_{3}, 400 \mathrm{MHz}\right) \delta 7.80(1 \mathrm{H}, \mathrm{dd}, J=7.9$, $\left.1.6 \mathrm{~Hz}, \mathrm{H}-6^{\prime}\right), 7.78(1 \mathrm{H}, \mathrm{d}, J=15.9 \mathrm{~Hz}, \mathrm{H}-\beta), 7.53(1 \mathrm{H}, \mathrm{td}, J=$ 7.9, 1.6 Hz, H-4 $\left.{ }^{\prime}\right), 7.31\left(1 \mathrm{H}, \mathrm{td}, J=7.9,1.6 \mathrm{~Hz}, \mathrm{H}-5^{\prime}\right), 7.16(1 \mathrm{H}$, d, $\left.J=7.9 \mathrm{~Hz}, \mathrm{H}-3^{\prime}\right), 7.08\left(1 \mathrm{H}, \mathrm{dd}, J=7.9,1.6 \mathrm{~Hz}, \mathrm{H}-6^{\prime \prime}\right), 7.05$ $\left(1 \mathrm{H}, \mathrm{dd}, J=7.9,1.6 \mathrm{~Hz}, \mathrm{H}-2^{\prime \prime}\right), 6.82\left(1 \mathrm{H}, \mathrm{d}, J=7.9 \mathrm{~Hz}, \mathrm{H}-5^{\prime \prime}\right)$, $6.47(1 \mathrm{H}, \mathrm{d}, J=15.9 \mathrm{~Hz}, \mathrm{H}-\alpha), 6.01\left(2 \mathrm{H}, \mathrm{s}, \mathrm{OCH}_{2} \mathrm{O}\right), 2.54(3 \mathrm{H}$, $\left.\mathrm{s}, \mathrm{CH}_{3}-2\right) ;{ }^{13} \mathrm{C} \mathrm{NMR}\left(\mathrm{CDCl}_{3}, 100 \mathrm{MHz}\right) \delta 197.8(\mathrm{C}-1), 165.4$ $(\mathrm{C}=\mathrm{O}), 150.2\left(\mathrm{C}-2^{\prime}\right), 149.2\left(\mathrm{C}-4^{\prime \prime}\right), 148.5\left(\mathrm{C}-3^{\prime \prime}\right), 147.1(\mathrm{C}-\beta)$, $133.3\left(\mathrm{C}-4^{\prime}\right), 131.5\left(\mathrm{C}-1^{\prime}\right), 130.1\left(\mathrm{C}-6^{\prime}\right), 128.5\left(\mathrm{C}-1^{\prime \prime}\right), 126.0$ $\left(\mathrm{C}-5^{\prime}\right), 125.2\left(\mathrm{C}-3^{\prime}\right), 123.8\left(\mathrm{C}-6^{\prime \prime}\right), 114.6(\mathrm{C}-\alpha), 108.6\left(\mathrm{C}-5^{\prime \prime}\right)$, $106.7\left(\mathrm{C}-2^{\prime \prime}\right), 101.7\left(\mathrm{OCH}_{2} \mathrm{O}\right), 29.9$ (C-2); EIMS (probe) $70 \mathrm{eV}$ $\left(\mathrm{m} / z\right.$, rel. int.) $310 \mathrm{M}^{+}(12), 175$ (100), 145 (64), 117 (24), 89 (40), 63 (16); calculated molecular mass: 310.30 .

2.4. Typical Procedure for the Synthesis of Substituted 3-Hydroxy-1-(2-hydroxyphenyl)-5-(phenyl)-2,4-pentadien-1ones $(\mathbf{4} \boldsymbol{a}-\mathbf{j})$. KOH powder $(0.05 \mathrm{mmol}, 2.8 \mathrm{~g})$ was added to a solution of 2-cinnamoyloxy acetophenones $\mathbf{3 a}-\mathbf{j}$ (10.0 $\mathrm{mmol})$ in $\mathrm{Me}_{2} \mathrm{SO}(15 \mathrm{~mL})$. The solution was stirred at room temperature until complete disappearance of the starting material, which was monitored by TLC. A typical reaction time was $2 \mathrm{~h}$. The solution was then poured into ice water and $\mathrm{HCl}(20 \mathrm{~mL})$ and the $\mathrm{pH}$ adjusted to 5 . The obtained solid was removed by filtration, dissolved in EtOAc $(150 \mathrm{~mL})$, and purified by silica gel chromatography using EtOAc : $n$-hexane $(7: 3)$ as the eluent. The solvent was evaporated to dryness, and the residue recrystallized from $\mathrm{EtOH}$, resulting in $\mathbf{4 a - j}$.

3-Hydroxy-1-(2-hydroxyphenyl)-5-(2-fluorophenyl)-2,4-

pentadien-1-one (4a). Pale yellow solid residue (93\% yield); $\mathrm{mp} 158-160^{\circ} \mathrm{C}$, IR (KBr) $v_{\max }: 1680(\mathrm{C}=\mathrm{O}), 1626,1581,1483$, $1283(\mathrm{C}-\mathrm{F}), 1227(\mathrm{C}-\mathrm{O}) \mathrm{cm}^{-1} ;{ }^{1} \mathrm{H} \mathrm{NMR}\left(\mathrm{CDCl}_{3}, 400 \mathrm{MHz}\right)$ $\delta 14.55$ (s, 3-OH), 12.17 (s, $\left.2^{\prime}-\mathrm{OH}\right), 7.73(1 \mathrm{H}, \mathrm{d}, J=16.0 \mathrm{~Hz}$, $\mathrm{H}-5), 7.69$ (1H, dd, $\left.J=8.0,1.4 \mathrm{~Hz}, \mathrm{H}-6^{\prime}\right), 7.54(1 \mathrm{H}, \mathrm{td}, J=$ 7.7, $\left.1.5 \mathrm{~Hz}, \mathrm{H}-6^{\prime \prime}\right), 7.43$ (1H, ddd, $J=8.5,7.1,1.4 \mathrm{~Hz}, \mathrm{H}-4^{\prime}$ ), 7.31-7.32 (1H, m, H- $\left.4^{\prime \prime}\right), 7.16\left(1 \mathrm{H}, \mathrm{t}, J=7.6 \mathrm{~Hz}, \mathrm{H}-5^{\prime \prime}\right), 7.09$ $\left(1 \mathrm{H}, \mathrm{t}, J=8.2 \mathrm{~Hz}, \mathrm{H}-3^{\prime \prime}\right), 6.97\left(1 \mathrm{H}, \mathrm{dd}, J=8.5,0.7 \mathrm{~Hz}, \mathrm{H}-3^{\prime}\right)$, $6.88\left(1 \mathrm{H}, \mathrm{t}, J=8.1 \mathrm{~Hz}, \mathrm{H}-5^{\prime}\right), 6.70(1 \mathrm{H}, \mathrm{d}, J=16.0 \mathrm{~Hz}, \mathrm{H}-4)$, $6.32(1 \mathrm{H}, \mathrm{s}, \mathrm{H}-2) ;{ }^{13} \mathrm{C} \mathrm{NMR}\left(\mathrm{CDCl}_{3}, 100 \mathrm{MHz}\right) \delta 196.5(\mathrm{C}-1)$, $174.0(\mathrm{C}-3), 162.6\left(\mathrm{C}-2^{\prime}\right), 161.4\left(\mathrm{~d}, J_{\mathrm{CF}}=253.8 \mathrm{~Hz}, \mathrm{C}-2^{\prime \prime}\right), 136.1$ $\left(\mathrm{C}-4^{\prime}\right), 132.6(\mathrm{~d}, J=2.2 \mathrm{~Hz}, \mathrm{C}-5), 131.4\left(\mathrm{~d}, J=8.8 \mathrm{~Hz}, \mathrm{C}-4^{\prime \prime}\right)$, $129.2\left(\mathrm{~d}, J=3.0 \mathrm{~Hz}, \mathrm{C}-6^{\prime \prime}\right), 128.6\left(\mathrm{C}-6^{\prime}\right), 124.8(\mathrm{~d}, J=7.8 \mathrm{~Hz}$, C-4), 124.5 (d, $\left.J=3.5 \mathrm{~Hz}, \mathrm{C}-5^{\prime \prime}\right), 123.1\left(\mathrm{~d}, J=11.5 \mathrm{~Hz}, \mathrm{C}-1^{\prime \prime}\right)$, $119.06\left(\mathrm{C}-5^{\prime}\right), 119.04\left(\mathrm{C}-1^{\prime}\right), 118.7\left(\mathrm{C}-3^{\prime}\right), 116.3(\mathrm{~d}, J=21.9 \mathrm{~Hz}$, $\left.\mathrm{C}-3^{\prime \prime}\right), 97.4(\mathrm{C}-2) ;{ }^{19} \mathrm{~F}$ NMR $\left(\mathrm{CDCl}_{3}, 376.5 \mathrm{MHz}\right) \delta-114.18$; EIMS (probe) $70 \mathrm{eV}\left(\mathrm{m} / z\right.$, rel. int.) $284 \mathrm{M}^{+}$(26), 264 (7), 149 (100), 121 (59), 101 (20); calculated molecular mass: 284.28.

3-Hydroxy-1-(2-hydroxyphenyl)-5-(3-fluorophenyl)-2,4pentadien-1-one $(\mathbf{4 b})$. Yellow solid residue (72\% yield), mp 
$115-117^{\circ} \mathrm{C}, \mathrm{IR}(\mathrm{KBr}) v_{\max }: 1641(\mathrm{C}=\mathrm{O}), 1626(\mathrm{C}=\mathrm{C}), 1581,1488$, 1429, 1294 (C-F), $1236 \mathrm{~cm}^{-1} ;{ }^{1} \mathrm{H}$ NMR $\left(\mathrm{CDCl}_{3}, 400 \mathrm{MHz}\right) \delta$ 14.55 (s, 3-OH), 12.15 (s, $\left.2^{\prime}-\mathrm{OH}\right), 7.68(1 \mathrm{H}, \mathrm{dd}, J=8.0,2.0 \mathrm{~Hz}$, H-6 $\left.{ }^{\prime}\right), 7.58(1 \mathrm{H}, \mathrm{d}, J=15.8 \mathrm{~Hz}, 1 \mathrm{H}, \mathrm{H}-5), 7.44(1 \mathrm{H}, \mathrm{ddd}, J=8.5$, $\left.7.1,1.5 \mathrm{~Hz}, \mathrm{H}-4^{\prime}\right), 7.34\left(1 \mathrm{H}, \mathrm{dd}, J=7.9,5.7 \mathrm{~Hz}, \mathrm{H}-5^{\prime \prime}\right), 7.30(1 \mathrm{H}$, d, $\left.J=7.8 \mathrm{~Hz}, \mathrm{H}-6^{\prime \prime}\right), 7.24-7.25\left(1 \mathrm{H}, \mathrm{m}, \mathrm{H}-2^{\prime \prime}\right), 7.06-7.07(1 \mathrm{H}$, m, H-4 $\left.{ }^{\prime \prime}\right), 6.89\left(1 \mathrm{H}, \mathrm{ddd}, J=8.0,7.1,0.9 \mathrm{~Hz}, \mathrm{H}-5^{\prime}\right), 6.97(1 \mathrm{H}$, dd, $\left.J=7.9,0.9 \mathrm{~Hz}, \mathrm{H}-3^{\prime}\right), 6.56(1 \mathrm{H}, \mathrm{d}, J=15.8 \mathrm{~Hz}, \mathrm{H}-4), 6.32$ $(1 \mathrm{H}, \mathrm{s}, \mathrm{H}-2) ;{ }^{13} \mathrm{C} \mathrm{NMR}\left(\mathrm{CDCl}_{3}, 100 \mathrm{MHz}\right) \delta 196.3(\mathrm{C}-1), 173.6$ (C-3), $164.9\left(\mathrm{~d}, J_{\mathrm{CF}}=247.2 \mathrm{~Hz}, \mathrm{C}-3^{\prime \prime}\right), 162.7\left(\mathrm{C}-2^{\prime}\right), 138.3(\mathrm{~d}, J$ $=2.5 \mathrm{~Hz}, \mathrm{C}-5), 137.3\left(\mathrm{~d}, J=7.8 \mathrm{~Hz}, \mathrm{C}-1^{\prime \prime}\right), 136.0\left(\mathrm{C}-4^{\prime}\right), 130.5$ $\left(\mathrm{d}, J=8.23 \mathrm{~Hz}, \mathrm{C}-5^{\prime \prime}\right), 128.5\left(\mathrm{C}-6^{\prime}\right), 124.1\left(\mathrm{~d}, J=2.8 \mathrm{~Hz}, \mathrm{C}-6^{\prime \prime}\right)$, 123.5 (C-4), $119.1\left(\mathrm{C}-5^{\prime}\right), 119.0\left(\mathrm{C}-1^{\prime}\right), 118.8\left(\mathrm{C}-3^{\prime}\right), 116.9$ (d, $J$ $\left.=21.6 \mathrm{~Hz}, \mathrm{C}-4^{\prime \prime}\right), 114.1\left(\mathrm{~d}, J=20.0 \mathrm{~Hz}, \mathrm{C}-2^{\prime \prime}\right), 97.4(\mathrm{C}-2) ;{ }^{19} \mathrm{~F}$ NMR $\left(\mathrm{CDCl}_{3}, 376.5 \mathrm{MHz}\right) \delta-112.32$; EIMS (probe) $70 \mathrm{eV}$ ( $m / z$, rel. int.) $284 \mathrm{M}^{+}$(25), 149 (100), 265 (8), 121 (88), 101 (17); calculated molecular mass: 284.28.

\section{3-Hydroxy-1-(2-hydroxyphenyl)-5-(4-fluorophenyl)-2,4-}

pentadien-1-one (4c). Pale yellow solid residue (92\% yield); $\mathrm{mp} 130-132^{\circ} \mathrm{C}$, IR (KBr) $v_{\max }: 1683(\mathrm{C}=\mathrm{O}), 1627$ (C=C), 1598, $1572,1489,1156(\mathrm{C}-\mathrm{F}) \mathrm{cm}^{-1} ;{ }^{1} \mathrm{H} \mathrm{NMR}\left(\mathrm{CDCl}_{3}, 400 \mathrm{MHz}\right) \delta$ $14.62(\mathrm{~s}, 3-\mathrm{OH}), 12.17\left(\mathrm{~s}, 2^{\prime}-\mathrm{OH}\right), 7.68(1 \mathrm{H}, \mathrm{dd}, J=8.0,1.4 \mathrm{~Hz}$, H- $\left.6^{\prime}\right), 7.60(1 \mathrm{H}, \mathrm{d}, J=16.0 \mathrm{~Hz}, \mathrm{H}-5), 7.52(2 \mathrm{H}, \mathrm{dd}, J=8.9$, $\left.5.4 \mathrm{~Hz}, \mathrm{H}-2^{\prime \prime} / 6^{\prime \prime}\right), 7.44$ (1H, ddd, $\left.J=8.5,7.1,1.4 \mathrm{~Hz}, \mathrm{H}-4^{\prime}\right)$, $7.08\left(2 \mathrm{H}, \mathrm{t}, J=8.9 \mathrm{~Hz}, \mathrm{H}-3^{\prime \prime} / 5^{\prime \prime}\right), 6.97(1 \mathrm{H}, \mathrm{dd}, J=8.5,0.9 \mathrm{~Hz}$, H- $\left.3^{\prime}\right), 6.88\left(1 \mathrm{H}\right.$, ddd, $\left.J=8.1,7.1,0.9 \mathrm{~Hz}, \mathrm{H}-5^{\prime}\right), 6.49(1 \mathrm{H}, \mathrm{d}, J=$ $16.0 \mathrm{~Hz}, \mathrm{H}-4), 6.29$ (1H, s, H-2); ${ }^{13} \mathrm{C} \mathrm{NMR}\left(\mathrm{CDCl}_{3}, 100 \mathrm{MHz}\right)$ $\delta 196.0(\mathrm{C}-1), 174.3(\mathrm{C}-3), 163.8\left(\mathrm{~d}, J_{\mathrm{CF}}=250.3 \mathrm{~Hz}, \mathrm{C}-4^{\prime \prime}\right)$, $162.6\left(\mathrm{C}-2^{\prime}\right), 138.5$ (C-5), $135.9\left(\mathrm{C}-4^{\prime}\right), 130.2$ (d, $J=3.5 \mathrm{~Hz}$, $\left.\mathrm{C}-1^{\prime \prime}\right), 129.8\left(\mathrm{~d}, J=8.2 \mathrm{~Hz}, \mathrm{C}-2^{\prime \prime} / 6^{\prime \prime}\right), 128.5\left(\mathrm{C}-6^{\prime}\right), 121.9(\mathrm{C}-4)$, $119.04\left(\mathrm{C}-1^{\prime} / 5^{\prime}\right), 118.8\left(\mathrm{C}-3^{\prime}\right), 116.2\left(\mathrm{~d}, J=21.9 \mathrm{~Hz}, \mathrm{C}-3^{\prime \prime} / 5^{\prime \prime}\right)$, 97.0 (C-2); ${ }^{19} \mathrm{~F} \mathrm{NMR}\left(\mathrm{CDCl}_{3}, 376.5 \mathrm{MHz}\right) \delta-109.55$; EIMS ( $\mathrm{m} / \mathrm{z}$, rel. int.) $284 \mathrm{M}^{+}$(21), 149 (100), 121 (71), 265 (4), 163 (16), 101 (18); calculated molecular mass: 284.28.

\section{3-Hydroxy-1-(2-hydroxyphenyl)-5-(3,5-difluorophenyl)-2,4-} pentadien-1-one $(\mathbf{4 d})$. Light brown solid residue (91\% yield), mp 130-132 C, IR (KBr) $v_{\max }$ : $1698(\mathrm{C}=\mathrm{O}), 1658(\mathrm{C}=\mathrm{C}), 1119$ (C-F), 962, $843 \mathrm{~cm}^{-1} ;{ }^{1} \mathrm{H}$ NMR $\left(\mathrm{CDCl}_{3}, 400 \mathrm{MHz}\right) \delta 14.46$ (s, 3-OH), 12.10 (s, $\left.2^{\prime}-\mathrm{OH}\right), 7.67\left(1 \mathrm{H}, \mathrm{dd}, J=8.0,1.4 \mathrm{~Hz}, \mathrm{H}-6^{\prime}\right)$, $7.51(1 \mathrm{H}, \mathrm{d}, J=15.7 \mathrm{~Hz}, \mathrm{H}-5), 7.45(1 \mathrm{H}$, ddd, $J=8.5,7.2,1.6 \mathrm{~Hz}$, $\left.\mathrm{H}-4^{\prime}\right), 7.04\left(1 \mathrm{H}, \mathrm{dd}, J=8.2,2.2 \mathrm{~Hz}, \mathrm{H}-2^{\prime \prime} / 6^{\prime \prime}\right), 6.98(1 \mathrm{H}, \mathrm{dd}, J$ $\left.=8.5,1.1 \mathrm{~Hz}, \mathrm{H}-3^{\prime}\right), 6.89\left(1 \mathrm{H}, \mathrm{ddd}, J=8.1,7.2,1.1 \mathrm{~Hz}, \mathrm{H}-5^{\prime}\right)$, $6.80\left(1 \mathrm{H}, \mathrm{tt}, J=8.8,2.2 \mathrm{~Hz}, \mathrm{H}-4^{\prime \prime}\right), 6.55(1 \mathrm{H}, \mathrm{d}, J=15.7 \mathrm{~Hz}$, $\mathrm{H}-4), 6.32(1 \mathrm{H}, \mathrm{s}, \mathrm{H}-2) ;{ }^{13} \mathrm{C} \mathrm{NMR}\left(\mathrm{CDCl}_{3}, 100 \mathrm{MHz}\right) \delta 196.4$ (C-1), 172.8 (C-3), $163.3\left(\mathrm{~d}, J_{\mathrm{CF}}=247.8 \mathrm{~Hz}, \mathrm{C}-3^{\prime \prime} / 5^{\prime \prime}\right), 162.7$ $\left(\mathrm{C}-2^{\prime}\right), 138.3\left(\mathrm{t}, J=9.5 \mathrm{~Hz}, \mathrm{C}-1^{\prime \prime}\right), 137.0(\mathrm{C}-5), 136.2\left(\mathrm{C}-4^{\prime}\right)$, $128.6\left(\mathrm{C}-6^{\prime}\right), 124.8$ (C-4), $119.1\left(\mathrm{C}-5^{\prime}\right), 118.94\left(\mathrm{C}-1^{\prime}\right), 118.85$ $\left(\mathrm{C}-3^{\prime}\right), 110.5\left(\mathrm{dd}, J=18.5,6.8 \mathrm{~Hz}, \mathrm{C}-2^{\prime \prime} / 6^{\prime \prime}\right), 105.1(\mathrm{~d}, J=$ $\left.25.6 \mathrm{~Hz}, \mathrm{C}-4^{\prime \prime}\right), 97.9(\mathrm{C}-2) ;{ }^{19} \mathrm{~F} \mathrm{NMR}\left(\mathrm{CDCl}_{3}, 376.5 \mathrm{MHz}\right)$ $\delta-109.10$; EIMS ( $m / z$, rel. int.) $302 \mathrm{M}^{+}$(28), 167 (100), 121 (76), 285 (10), 139 (29), 121 (76); calculated molecular mass: 302.27 .

3-Hydroxy-1-(4-fluoro-2-hydroxyphenyl)-5-(4-fluorophenyl)2,4-pentadien-1-one (4e). Yellow solid residue (82\% yield); $\mathrm{mp} 143-145^{\circ} \mathrm{C}$; IR (KBr) $v_{\max }: 1726(\mathrm{C}=\mathrm{O}), 1629(\mathrm{C}=\mathrm{C})$, $1234(\mathrm{C}-\mathrm{F}), 1157,975,824,803,789 \mathrm{~cm}^{-1} ;{ }^{1} \mathrm{H}$ NMR $\left(\mathrm{CDCl}_{3}\right.$,
$400 \mathrm{MHz}) \delta 14.42(\mathrm{~s}, 3-\mathrm{OH}), 12.47\left(\mathrm{~s}, 2^{\prime}-\mathrm{OH}\right), 7.60(1 \mathrm{H}, \mathrm{d}$, $J=15.9 \mathrm{~Hz}, \mathrm{H}-5), 7.68\left(1 \mathrm{H}, \mathrm{dd}, J=9.0,6.4 \mathrm{~Hz}, \mathrm{H}-6^{\prime}\right), 7.52$ $\left(1 \mathrm{H}, \mathrm{dd}, J=8.7,5.4 \mathrm{~Hz}, \mathrm{H}-2^{\prime \prime} / 6^{\prime \prime}\right), 7.08(2 \mathrm{H}, \mathrm{t}, J=8.6 \mathrm{~Hz}$, $\left.\mathrm{H}-3^{\prime \prime} / 5^{\prime \prime}\right), 6.65\left(1 \mathrm{H}, \mathrm{dd}, J=10.4,2.5 \mathrm{~Hz}, \mathrm{H}-3^{\prime}\right), 6.60(1 \mathrm{H}, \mathrm{ddd}$, $\left.J=8.8,8.2,2.2 \mathrm{~Hz},{\mathrm{H}-5^{\prime}}^{\prime}\right), 6.51(1 \mathrm{H}, \mathrm{d}, J=15.9 \mathrm{~Hz}, \mathrm{H}-4), 6.20$ $(1 \mathrm{H}, \mathrm{s}, \mathrm{H}-2) ;{ }^{13} \mathrm{C} \mathrm{NMR}\left(\mathrm{CDCl}_{3}, 100 \mathrm{MHz}\right) \delta 194.9(\mathrm{C}-1), 174.2$ $(\mathrm{C}-3), 166.4\left(\mathrm{~d}, J_{\mathrm{CF}}=212.1 \mathrm{~Hz}, \mathrm{C}-4^{\prime}\right), 165.2(\mathrm{~d}, J=14.1 \mathrm{~Hz}$, C-2' $\left.{ }^{\prime}\right), 163.0\left(\mathrm{~d}, J_{\mathrm{CF}}=252.6 \mathrm{~Hz}, \mathrm{C}-4^{\prime \prime}\right), 138.7(\mathrm{C}-5), 130.7(\mathrm{~d}$, $\left.J=11.9 \mathrm{~Hz}, \mathrm{C}-1^{\prime \prime}\right), 130.4\left(\mathrm{~d}, J=10.8 \mathrm{~Hz}, \mathrm{C}-6^{\prime}\right), 129.9$ (d, $J=$ $\left.8.6 \mathrm{~Hz}, \mathrm{C}-2^{\prime \prime} / 6^{\prime \prime}\right), 121.7(\mathrm{C}-4), 116.2\left(\mathrm{~d}, J=21.9 \mathrm{~Hz}, \mathrm{C}-3^{\prime \prime} / 5^{\prime \prime}\right)$, $116.0\left(\mathrm{C}-1^{\prime}\right), 107.3\left(\mathrm{~d}, J=22.6 \mathrm{~Hz}, \mathrm{C}-5^{\prime}\right), 105.3(\mathrm{~d}, J=23.6 \mathrm{~Hz}$, $\left.\mathrm{C}-3^{\prime}\right)$, 96.7 (C-2); ${ }^{19} \mathrm{~F}$ NMR $\left(\mathrm{CDCl}_{3}, 376.5 \mathrm{MHz}\right) \delta-100.64$, -109.57; EIMS ( $m / z$, rel. int.) $302 \mathrm{M}^{+}$(41), 149 (100), 283 (18), 207 (11), 163 (35), 139 (95), 121 (37), 101 (35); calculated molecular mass: 302.27 .

\section{3-Hydroxy-1-(4-fluoro-2-hydroxyphenyl)-5-phenyl-2,4-} pentadien-1-one $(4 f)$. Yellow solid residue (64\% yield); $\mathrm{mp}$ $143-145^{\circ} \mathrm{C}$; IR (KBr) $v_{\max }: 1632(\mathrm{C}=\mathrm{O}), 1579$ (C=C), 1178 $(\mathrm{C}-\mathrm{F}) \mathrm{cm}^{-1} ;{ }^{1} \mathrm{H} \mathrm{NMR}\left(\mathrm{CDCl}_{3}, 400 \mathrm{MHz}\right) \delta 14.48(\mathrm{~s}, 3-\mathrm{OH})$, $12.55\left(\mathrm{~s}, 2^{\prime}-\mathrm{OH}\right), 7.68\left(1 \mathrm{H}, \mathrm{dd}, J=8.9,6.4 \mathrm{~Hz}, \mathrm{H}-6^{\prime}\right), 7.64$ $(1 \mathrm{H}, \mathrm{d}, J=15.8 \mathrm{~Hz}, \mathrm{H}-5), 7.53$ (dd, $J=8.1,2.1 \mathrm{~Hz}, \mathrm{H}-2^{\prime \prime} / 6^{\prime \prime}$ ), 7.37-7.39 (3H, m, H-3" $\left./ 4^{\prime \prime} / 5^{\prime \prime}\right), 6.65(\mathrm{dd}, J=10.3,2.5 \mathrm{~Hz}$, $\left.\mathrm{H}-3^{\prime}\right), 6.60\left(1 \mathrm{H}, \mathrm{td}, J=8.0,2.50 \mathrm{~Hz}, \mathrm{H}-5^{\prime}\right), 6.57(1 \mathrm{H}, \mathrm{d}, J=$ $15.8 \mathrm{~Hz}, \mathrm{H}-4), 6.21(1 \mathrm{H}, \mathrm{s}, \mathrm{H}-2) ;{ }^{13} \mathrm{C} \mathrm{NMR}\left(\mathrm{CDCl}_{3}, 100 \mathrm{MHz}\right)$ $\delta 194.9(\mathrm{C}-1), 174.4(\mathrm{C}-3), 165.2\left(\mathrm{~d}, J_{\mathrm{CF}}=209.2 \mathrm{~Hz}, \mathrm{C}-4^{\prime}\right)$, $165.1\left(\mathrm{~d}, J=14.1 \mathrm{~Hz}, \mathrm{C}-2^{\prime}\right), 140.1(\mathrm{C}-5), 134.9\left(\mathrm{C}-1^{\prime \prime}\right), 130.5$ $\left(\mathrm{d}, J=11.7 \mathrm{~Hz}, \mathrm{C}-6^{\prime}\right), 130.2\left(\mathrm{C}-4^{\prime \prime}\right), 129.0\left(\mathrm{C}-3^{\prime \prime} / 5^{\prime \prime}\right), 128.0$ $\left(\mathrm{C}-2^{\prime \prime} / 6^{\prime \prime}\right), 122.0(\mathrm{C}-4), 116.0\left(\mathrm{C}-1^{\prime}\right), 107.3(\mathrm{~d}, J=22.7 \mathrm{~Hz}$, $\left.\mathrm{C}-5^{\prime}\right), 105.3\left(\mathrm{~d}, J=23.4 \mathrm{~Hz}, \mathrm{C}-3^{\prime}\right), 96.8(\mathrm{C}-2) ;{ }^{19} \mathrm{~F}\left(\mathrm{CDCl}_{3}\right.$, $376.5 \mathrm{MHz}) \delta-100.72$; EIMS $\left(m / z\right.$, rel. int.) $284 \mathrm{M}^{+}(33), 131$ (100), 265 (14), 139 (64), 103 (42), 77 (39), 51 (11); calculated molecular mass: 284.28 .

3-Hydroxy-1-(5-fluoro-2-hydroxyphenyl)-5-phenyl-2,4-pentadien-1-one $(\mathbf{4 g})$. Yellow solid residue (90\% yield); mp 118$120^{\circ} \mathrm{C}$; IR (KBr): 1632 (C=O), 1550, 1487, 1248, 1180, 960, 781, $754 \mathrm{~cm}^{-1} ;{ }^{1} \mathrm{H} \mathrm{NMR}\left(\mathrm{CDCl}_{3}, 400 \mathrm{MHz}\right) \delta 14.59$ (s, 3-OH), 11.94 (s, $\left.2^{\prime}-\mathrm{OH}\right), 7.66(1 \mathrm{H}, \mathrm{d}, J=15.8 \mathrm{~Hz}, \mathrm{H}-5), 7.54(2 \mathrm{H}, \mathrm{dd}$, $\left.J=7.9,2.2 \mathrm{~Hz}, \mathrm{H}-2^{\prime \prime} / 6^{\prime \prime}\right), 7.39-7.41\left(3 \mathrm{H}, \mathrm{m}, \mathrm{H}-3^{\prime \prime} / 4^{\prime \prime} / 5^{\prime \prime}\right)$, $7.34\left(1 \mathrm{H}, \mathrm{dd}, J=9.0,3.0 \mathrm{~Hz}, \mathrm{H}-6^{\prime}\right), 7.17(1 \mathrm{H}, \mathrm{ddd}, J=9.2,3.0$, $\left.1.3 \mathrm{~Hz}, \mathrm{H}-4^{\prime}\right), 6.93\left(1 \mathrm{H}, \mathrm{dd}, J=9.1,4.7 \mathrm{~Hz}, \mathrm{H}-3^{\prime}\right), 6.58(1 \mathrm{H}$, $\mathrm{d}, J=15.8 \mathrm{~Hz}, \mathrm{H}-4), 6.20(1 \mathrm{H}, \mathrm{s}, \mathrm{H}-2) ;{ }^{13} \mathrm{C} \mathrm{NMR}\left(\mathrm{CDCl}_{3}\right.$, $100 \mathrm{MHz}) \delta 194.8(\mathrm{~d}, J=2.7 \mathrm{~Hz}, \mathrm{C}-1), 175.2(\mathrm{C}-3), 158.7$ $\left(\mathrm{C}-2^{\prime}\right), 155.1\left(\mathrm{~d}, J_{\mathrm{CF}}=236.8 \mathrm{~Hz}, \mathrm{C}-5^{\prime}\right), 140.6(\mathrm{C}-5), 134.8$ $\left(\mathrm{C}-1^{\prime \prime}\right), 130.4\left(\mathrm{C}-4^{\prime \prime}\right), 129.0\left(\mathrm{C}-3^{\prime \prime} / 5^{\prime \prime}\right), 128.1\left(\mathrm{C}-2^{\prime \prime} / 6^{\prime \prime}\right), 123.2$ $\left(\mathrm{d}, J=23.4 \mathrm{~Hz}, \mathrm{C}-4^{\prime}\right), 121.9(\mathrm{C}-4), 120.0\left(\mathrm{~d}, J=7.41 \mathrm{~Hz}, \mathrm{C}-3^{\prime}\right)$, $118.7\left(\mathrm{~d}, J=6.5 \mathrm{~Hz}, \mathrm{C}-1^{\prime}\right), 113.46\left(\mathrm{~d}, J=23.5 \mathrm{~Hz}, \mathrm{C}-6^{\prime}\right), 96.8$ $(\mathrm{C}-2) ;{ }^{19} \mathrm{~F}\left(\mathrm{CDCl}_{3}, 376.5 \mathrm{MHz}\right) \delta-124.33$; EIMS (probe) $70 \mathrm{eV}\left(\mathrm{m} / z\right.$, rel. int.) $284 \mathrm{M}^{+}$(5), 131 (100), 103 (80), 77 (35); calculated molecular mass: 284.28.

3-Hydroxy-1-(2-hydroxyphenyl)-5-(4-methoxyphenyl)-2,4pentadien-1-one $(\mathbf{4 h})$. Yellow solid residue (90\% yield); $\mathrm{mp}$ $167-169^{\circ} \mathrm{C}$ (lit. $\left.162-164^{\circ} \mathrm{C}[38]\right)$; IR (KBr) $v_{\max }: 1645$ (C=O), $1599,1514,1462,1258,963,828,749 \mathrm{~cm}^{-1} ;{ }^{1} \mathrm{H} \mathrm{NMR}\left(\mathrm{CDCl}_{3}\right.$, $400 \mathrm{MHz}) \delta 14.72(\mathrm{~s}, 3-\mathrm{OH}), 12.24\left(\mathrm{~s}, 2^{\prime}-\mathrm{OH}\right), 7.67(1 \mathrm{H}, \mathrm{dd}, J$ $\left.=8.0,1.6 \mathrm{~Hz}, \mathrm{H}-6^{\prime}\right), 7.61(1 \mathrm{H}, \mathrm{d}, J=15.8 \mathrm{~Hz}, \mathrm{H}-5), 7.49(2 \mathrm{H}, \mathrm{d}$, $\left.J=8.8 \mathrm{~Hz}, \mathrm{H}-2^{\prime \prime} / 6^{\prime \prime}\right), 7.42\left(1 \mathrm{H}, \mathrm{ddd}, J=8.5,7.5,1.6 \mathrm{~Hz}, \mathrm{H}-4^{\prime}\right)$, 
$6.96\left(1 \mathrm{H}, \mathrm{dd}, J=8.5,2.1 \mathrm{~Hz}, \mathrm{H}-3^{\prime}\right), 6.91(2 \mathrm{H}, \mathrm{d}, J=8.8 \mathrm{~Hz}$, $\left.\mathrm{H}-3^{\prime \prime} / 5^{\prime \prime}\right), 6.88-6.89\left(1 \mathrm{H}, \mathrm{m}, \mathrm{H}-5^{\prime}\right), 6.45$ (d, $\left.J=15.8 \mathrm{~Hz}, \mathrm{H}-4\right)$, $6.26(1 \mathrm{H}, \mathrm{s}, \mathrm{H}-2), 3.83\left(\mathrm{~s}, 3 \mathrm{H}, \mathrm{OCH}_{3}\right) ;{ }^{13} \mathrm{C} \mathrm{NMR}\left(\mathrm{CDCl}_{3}\right.$, $100 \mathrm{MHz}) \delta 195.3(\mathrm{C}-1), 174.9(\mathrm{C}-3), 162.3\left(\mathrm{C}-2^{\prime}\right), 161.1\left(\mathrm{C}-4^{\prime \prime}\right)$, 139.5 (C-5), $135.3\left(\mathrm{C}-4^{\prime}\right), 129.8\left(\mathrm{C}-1^{\prime \prime}\right), 129.4\left(\mathrm{C}-2^{\prime \prime} / 6^{\prime \prime}\right), 128.8$ $\left(\mathrm{C}-6^{\prime}\right), 119.4(\mathrm{C}-4), 118.9\left(\mathrm{C}-1^{\prime}\right), 118.7\left(\mathrm{C}-5^{\prime}\right), 118.44\left(\mathrm{C}-3^{\prime}\right)$, $114.2\left(\mathrm{C}-3^{\prime \prime} / 5^{\prime \prime}\right), 96.1(\mathrm{C}-2), 55.2\left(\mathrm{OCH}_{3}\right)$; EIMS (probe) $70 \mathrm{eV}\left(\mathrm{m} / z\right.$, rel. int.) $296 \mathrm{M}^{+}$(14), 161 (100), 207 (18), 133 (77), 118 (29); calculated molecular mass: 296.10.

\section{3-Hydroxy-1-(2-hydroxyphenyl)-5-(3,4-dimethoxyphenyl)-}

2,4-pentadien-1-one (4i). Yellow solid residue (84\% yield); mp 130-132 ${ }^{\circ} \mathrm{C}$ (lit. $136-138^{\circ} \mathrm{C}$ [37]); IR (KBr): 1685 (C=O), 1621, $1564,1488,1252,1161 ;{ }^{1} \mathrm{H}$ NMR $\left(\mathrm{CDCl}_{3}, 400 \mathrm{MHz}\right) \delta 14.71(\mathrm{~s}$, 3-OH), 12.23 (s, $\left.2^{\prime}-\mathrm{OH}\right), 7.67\left(1 \mathrm{H}, \mathrm{dd}, J=8.1,1.5 \mathrm{~Hz}, \mathrm{H}-6^{\prime}\right)$, $7.59(1 \mathrm{H}, \mathrm{d}, J=15.8 \mathrm{~Hz}, \mathrm{H}-5), 7.42(1 \mathrm{H}, \mathrm{ddd}, J=8.5,8.3,1.5 \mathrm{~Hz}$, $\left.\mathrm{H}-4^{\prime}\right), 7.11\left(\mathrm{dd}, J=8.3,1.9 \mathrm{~Hz}, \mathrm{H}-6^{\prime \prime}\right), 7.1\left(\mathrm{~d}, J=1.8 \mathrm{~Hz}, \mathrm{H}-2^{\prime \prime}\right)$, $6.96\left(1 \mathrm{H}, \mathrm{dd}, J=8.4,0.7 \mathrm{~Hz}, \mathrm{H}-3^{\prime}\right), 6.87(1 \mathrm{H}, \mathrm{d}, J=8.3 \mathrm{~Hz}$, $\left.\mathrm{H}-5^{\prime \prime}\right), 6.85\left(1 \mathrm{H}, \mathrm{td}, J=8.3,0.7 \mathrm{~Hz}, \mathrm{H}-5^{\prime}\right), 6.45(1 \mathrm{H}, \mathrm{d}, J=$ $15.8 \mathrm{~Hz}, \mathrm{H}-4), 6.28$ (1H, s, H-2), $3.92\left(3 \mathrm{H}, \mathrm{s}, 4^{\prime}-\mathrm{OCH}_{3}\right), 3.91$ $\left(3 \mathrm{H}, \mathrm{s}, 3^{\prime}-\mathrm{OCH}_{3}\right) ;{ }^{13} \mathrm{C} \mathrm{NMR}\left(\mathrm{CDCl}_{3}, 100 \mathrm{MHz}\right) \delta 195.6(\mathrm{C}-1)$, 175.0 (C-3), $162.5\left(\mathrm{C}-2^{\prime}\right), 151.1\left(\mathrm{C}-3^{\prime \prime}\right), 149.3\left(\mathrm{C}-4^{\prime \prime}\right), 140.0$ $(\mathrm{C}-5), 135.6\left(\mathrm{C}-4^{\prime}\right), 128.4\left(\mathrm{C}-6^{\prime}\right), 128.0\left(\mathrm{C}-1^{\prime \prime}\right), 122.6\left(\mathrm{C}-6^{\prime \prime}\right)$, 119.9 (C-4), $119.1\left(\mathrm{C}-1^{\prime}\right), 119.0\left(\mathrm{C}-5^{\prime}\right), 118.7\left(\mathrm{C}-3^{\prime}\right), 111.2\left(\mathrm{C}-5^{\prime \prime}\right)$, $109.7\left(\mathrm{C}-2^{\prime \prime}\right), 96.5(\mathrm{C}-2), 56.0\left(3^{\prime \prime}-\mathrm{OCH}_{3}\right), 55.93\left(4^{\prime \prime}-\mathrm{OCH}_{3}\right)$; EIMS (probe) $70 \mathrm{eV}\left(\mathrm{m} / z\right.$, rel. int.) $326 \mathrm{M}^{+}$(15), 191 (100), 207 (16), 163 (49), 148 (19), 133 (18), 77 (23); calculated molecular mass: 326.12 .

3-Hydroxy-1-(2-hydroxyphenyl)-5-(3,4-methylenedioxyphenyl)-2,4-pentadien-1-one (4j). Light yellow solid residue ( $94 \%$ yield); mp $165-167^{\circ} \mathrm{C}$; IR (KBr) $v_{\max }$ : $1693(\mathrm{C}=\mathrm{O}), 1621,1602$, 1566, 1484, 1446, 1239 (C-O), 1171, 1035, $925 \mathrm{~cm}^{-1} ;{ }^{1} \mathrm{H}$ NMR $\left(\mathrm{CDCl}_{3}, 400 \mathrm{MHz}\right) \delta 14.68(\mathrm{~s}, 3-\mathrm{OH}), 12.21\left(\mathrm{~s}, 2^{\prime}-\mathrm{OH}\right), 7.66$ $\left(1 \mathrm{H}, \mathrm{dd}, J=8.0,1.6 \mathrm{~Hz}, \mathrm{H}-6^{\prime}\right), 7.55(1 \mathrm{H}, \mathrm{d}, J=15.8 \mathrm{~Hz}, \mathrm{H}-5)$, $7.42\left(1 \mathrm{H}, \mathrm{ddd}, J=8.5,8.0,1.6 \mathrm{~Hz}, \mathrm{H}-4^{\prime}\right), 7.04(1 \mathrm{H}, \mathrm{bd}, J=$ $\left.0.35 \mathrm{~Hz}, \mathrm{H}-2^{\prime \prime}\right), 7.02\left(1 \mathrm{H}, \mathrm{dd}, J=8.0,1.2 \mathrm{~Hz}, \mathrm{H}-6^{\prime \prime}\right), 6.96$ $\left(1 \mathrm{H}, \mathrm{dd}, J=8.5,0.5 \mathrm{~Hz}, \mathrm{H}-3^{\prime}\right), 6.87(1 \mathrm{H}, \mathrm{td}, J=8.0,0.5 \mathrm{~Hz}$,

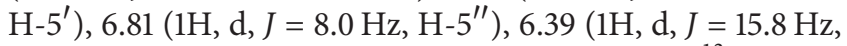
$\mathrm{H}-4), 6.26(1 \mathrm{H}, \mathrm{s}, \mathrm{H}-2), 6.00\left(2 \mathrm{H}, \mathrm{s}, \mathrm{OCH}_{2} \mathrm{O}\right) ;{ }^{13} \mathrm{C} \mathrm{NMR}$ $\left(\mathrm{CDCl}_{3}, 100 \mathrm{MHz}\right) \delta 195.7(\mathrm{C}-1), 174.8(\mathrm{C}-3), 162.6\left(\mathrm{C}-2^{\prime}\right)$, $149.6\left(\mathrm{C}-3^{\prime \prime}\right), 148.5\left(\mathrm{C}-4^{\prime \prime}\right), 139.7(\mathrm{C}-5), 135.7\left(\mathrm{C}-4^{\prime}\right), 129.5$ $\left(\mathrm{C}-1^{\prime \prime}\right), 128.4\left(\mathrm{C}-6^{\prime}\right), 124.6\left(\mathrm{C}-6^{\prime \prime}\right), 120.1(\mathrm{C}-4), 119.1\left(\mathrm{C}-1^{\prime}\right)$, 119.0 (C-5'), $118.73\left(\mathrm{C}-3^{\prime}\right), 108.7\left(\mathrm{C}-5^{\prime \prime}\right), 106.3\left(\mathrm{C}-2^{\prime \prime}\right), 101.6$ $\left(\mathrm{OCH}_{2} \mathrm{O}\right), 96.6$ (C-2); EIMS (probe) $70 \mathrm{eV}(\mathrm{m} / z$, rel. int.) $310 \mathrm{M}^{+}$(18), 175 (100), 207 (28), 145 (87), 157 (42), 117 (44), 89 (52), 43 (62); calculated molecular mass: 310.30 .

2.5. Typical Procedure for the Synthesis of Substituted 2Styrylchromones $(\mathbf{5} \boldsymbol{a}-\mathbf{j})$. p-Toluenesulfonic acid $(3.42 \mathrm{mmol}$, $0.59 \mathrm{~g})$ was added to a solution of the appropriate 3-hydroxy1-(2-hydroxyphenyl)-5-(phenyl)-2,4-pentadien-1-ones $\mathbf{4 a - j}$ $(6.5 \mathrm{mmol})$ in $\mathrm{Me}_{2} \mathrm{SO}(20 \mathrm{~mL})$. The reaction mixture was heated at $90^{\circ} \mathrm{C}$ for $2 \mathrm{~h}$ and then poured into ice and water $(20 \mathrm{~mL})$ and stirred for $10 \mathrm{~min}$. The obtained solid was removed by filtration, dissolved in $\mathrm{CHCl}_{3}(100 \mathrm{~mL})$, and washed with a $20 \%$ aqueous solution of sodium thiosulphate $(3 \times 10 \mathrm{~mL})$. The solvent was evaporated to dryness, and the residue was purified by silica gel chromatography, using $\mathrm{CHCl}_{3}: n$-hexane $(7: 3)$ as the eluent, to produce $\mathbf{5 a - j}$.

$2^{\prime}$-Fluro-2-styrylchromone (5a). Light yellow solid residue (68\% yield); mp $150-152^{\circ} \mathrm{C}$; UV $\lambda_{\max }\left(\mathrm{CH}_{3} \mathrm{OH}\right) \mathrm{nm}(\log \varepsilon)$ : 325 (3.37); IR (KBr) $v_{\max }: 1682(\mathrm{C}=\mathrm{O}), 1625,1589$ (C-C), 1562, 1464,1391 (C-F), 1125, $968 \mathrm{~cm}^{-1} ;{ }^{1} \mathrm{H} \mathrm{NMR}\left(\mathrm{CDCl}_{3}, 400 \mathrm{MHz}\right)$ $\delta 8.17(1 \mathrm{H}, \mathrm{dd}, J=7.9,1.6 \mathrm{~Hz}, \mathrm{H}-5), 7.72(1 \mathrm{H}, \mathrm{d}, J=16.2 \mathrm{~Hz}, \mathrm{H}-$ $\beta), 7.66(1 \mathrm{H}, \mathrm{ddd}, J=8.6,7.2,1.6 \mathrm{~Hz}, \mathrm{H}-7), 7.59$ (1H-td, $J=$ 7.6, $\left.1.5 \mathrm{~Hz}, \mathrm{H}-6^{\prime}\right), 7.53(1 \mathrm{H}, \mathrm{d}, J=8.3 \mathrm{~Hz}, \mathrm{H}-8), 7.37(1 \mathrm{H}, \mathrm{td}$, $J=7.9,0.8 \mathrm{~Hz}, \mathrm{H}-6), 7.31-7.32\left(1 \mathrm{H}, \mathrm{m}, \mathrm{H}-4^{\prime}\right), 7.17(1 \mathrm{H}, \mathrm{t}, J=$ $\left.7.9 \mathrm{~Hz}, \mathrm{H}-5^{\prime}\right), 7.11\left(1 \mathrm{H}, \mathrm{ddd}, J=9.2,8.2,2.4 \mathrm{~Hz}, \mathrm{H}-3^{\prime}\right), 6.87$ $(1 \mathrm{H}, \mathrm{d}, J=16.2 \mathrm{~Hz}, \mathrm{H}-\alpha), 6.32(1 \mathrm{H}, \mathrm{s}, \mathrm{H}-3) ;{ }^{13} \mathrm{C} \mathrm{NMR}\left(\mathrm{CDCl}_{3}\right.$, $100 \mathrm{MHz}) \delta 178.5(\mathrm{C}-4), 161.5(\mathrm{C}-2), 161.2\left(\mathrm{~d}, J_{\mathrm{CF}}=253.3 \mathrm{~Hz}\right.$, C-2' $\left.{ }^{\prime}\right), 156.0(\mathrm{C}-9), 133.9(\mathrm{C}-7), 131.3\left(\mathrm{~d}, J=8.7 \mathrm{~Hz}, \mathrm{C}-4^{\prime}\right), 129.5$ $(\mathrm{d}, J=3.1 \mathrm{~Hz}, \mathrm{C}-\beta), 128.4\left(\mathrm{~d}, J=2.7 \mathrm{~Hz}, \mathrm{C}-6^{\prime}\right), 125.7(\mathrm{C}-5)$, 125.1 (C-6), 124.6 (d, $\left.J=3.6 \mathrm{~Hz}, \mathrm{C}-5^{\prime}\right), 124.1$ (C-10), 123.1 (d, $J$ $\left.=11.7 \mathrm{~Hz}, \mathrm{C}-1^{\prime}\right), 122.7(\mathrm{~d}, J=6.5 \mathrm{~Hz}, \mathrm{C}-\alpha), 117.9(\mathrm{C}-8), 116.2(\mathrm{~d}$, $\left.J=21.8 \mathrm{~Hz}, \mathrm{C}-3^{\prime}\right), 111.2(\mathrm{C}-3) ;{ }^{19} \mathrm{~F} \mathrm{NMR}\left(\mathrm{CDCl}_{3}, 376.5 \mathrm{MHz}\right)$ $\delta$-115.39; EIMS ( $m / z$, rel. int.) $265\left(\mathrm{M}^{+}-1\right)(100), 237$ (12), 207 (20), 146 (36), 92 (25); HRMS $(m / z) \mathrm{M}^{+} 266.0733$ (calculated for $\mathrm{C}_{17} \mathrm{H}_{11} \mathrm{FO}_{2}$ : 266.0743).

$3^{\prime}$-Fluro-2-styrylchromone $(\mathbf{5 b})$. Brown solid residue $(62 \%$ yield), mp $105-108^{\circ} \mathrm{C}$; UV $\lambda_{\max }\left(\mathrm{CH}_{3} \mathrm{OH}\right) \mathrm{nm}(\log \varepsilon): 325$ (3.34); IR (KBr) $v_{\max }$ : $1694(\mathrm{C}=\mathrm{O}), 1622,1579$ (C-C), 1465, 1389 (C-F), 1247, 1122, 967, $775 \mathrm{~cm}^{-1} ;{ }^{1} \mathrm{H}$ NMR $\left(\mathrm{CDCl}_{3}\right.$, $400 \mathrm{MHz}) \delta 8.18(\mathrm{dd}, J=7.9,1.6 \mathrm{~Hz}, \mathrm{H}-5), 7.68(\mathrm{dt}, J=8.6$, $1.6 \mathrm{~Hz}, \mathrm{H}-7), 7.52$ (d, $J=8.3 \mathrm{~Hz}, \mathrm{H}-8), 7.55(1 \mathrm{H}, \mathrm{d}, J=16.0 \mathrm{~Hz}$, H- $\beta$ ), 7.35-7.37 (3H, m, H-5'/6 $/ 6)$, 7.26-7.27 (1H, m, H-2 ${ }^{\prime}$ ), $7.06\left(1 \mathrm{H}, \mathrm{d}, J=6.8 \mathrm{~Hz}, \mathrm{H}-4^{\prime}\right), 6.77(1 \mathrm{H}, \mathrm{d}, J=16.0 \mathrm{~Hz}, \mathrm{H}-\alpha)$, $6.34(1 \mathrm{H}, \mathrm{s}, \mathrm{H}-3) ;{ }^{13} \mathrm{C} \mathrm{NMR}\left(\mathrm{CDCl}_{3}, 100 \mathrm{MHz}\right) \delta 178.5(\mathrm{C}-$ 4), $163.2\left(\mathrm{~d}, J_{\mathrm{CF}}=245.5 \mathrm{~Hz}, \mathrm{C}-3^{\prime}\right), 161.2(\mathrm{C}-2), 156.0(\mathrm{C}-9)$, $137.3\left(\mathrm{~d}, J=7.8 \mathrm{~Hz}, \mathrm{C}-1^{\prime}\right), 135.6(\mathrm{~d}, J=2.8 \mathrm{~Hz}, \mathrm{C}-\beta), 133.9$ (C7), 130.5 (d, $\left.J=8.3 \mathrm{~Hz}, \mathrm{C}-5^{\prime}\right), 125.8$ (C-5), 125.1 (C-6), 124.1 (C-10), 123.61 (d, $\left.J=2.7 \mathrm{~Hz}, \mathrm{C}-6^{\prime}\right), 121.7(\mathrm{C}-\alpha), 117.9(\mathrm{C}-8)$, $116.7\left(\mathrm{~d}, J=21.6 \mathrm{~Hz}, \mathrm{C}-4^{\prime}\right), 114.0\left(\mathrm{~d}, J=22.0 \mathrm{~Hz}, \mathrm{C}-2^{\prime}\right), 111.2$ $(\mathrm{C}-3) ;{ }^{19} \mathrm{~F} \mathrm{NMR}\left(\mathrm{CDCl}_{3}, 376.5 \mathrm{MHz}\right) \delta-108.99$; EIMS $(\mathrm{m} / z$, rel. int.) $265\left(\mathrm{M}^{+}-1\right)(100), 237$ (6), 209 (8), 173 (16), 146 (40), 121 (20), 92 (27); HRMS $(\mathrm{m} / z)$ : $266.0726 \mathrm{M}^{+}$(calculated for $\left.\mathrm{C}_{17} \mathrm{H}_{11} \mathrm{FO}_{2}: 266.0743\right)$.

$4^{\prime}$-Fluoro-2-styrylchromone $(\mathbf{5 c})$. Off-white solid residue (70\% yield), mp $158-160^{\circ} \mathrm{C}$; UV $\lambda_{\max }\left(\mathrm{CH}_{3} \mathrm{OH}\right) \mathrm{nm}(\log \varepsilon)$ : 328 (3.39); IR (KBr): 1691 (C=O), 1623, 1594, 1506, 1466, 1391 (C-F), 1224, 969, $817 \mathrm{~cm}^{-1} ;{ }^{1} \mathrm{H} \mathrm{NMR}\left(\mathrm{CDCl}_{3}, 400 \mathrm{MHz}\right) \delta$ $8.01(1 \mathrm{H}, \mathrm{dd}, J=7.9,1.4 \mathrm{~Hz}, \mathrm{H}-5), 7.81-7.82$ (1H, m, H-7), 7.79 $\left(2 \mathrm{H}, \mathrm{m}, \mathrm{H}-2^{\prime} / 6^{\prime}\right), 7.70(1 \mathrm{H}, \mathrm{d}, J=16.2 \mathrm{~Hz}, \mathrm{H}-\beta), 7.69(1 \mathrm{H}, \mathrm{d}$, $J=8.5 \mathrm{~Hz}, \mathrm{H}-8), 7.47(1 \mathrm{H}, \mathrm{t}, J=7.4 \mathrm{~Hz}, \mathrm{H}-6), 7.28(2 \mathrm{H}, \mathrm{t}, J=$ $\left.8.8 \mathrm{~Hz}, \mathrm{H}-3^{\prime} / 5^{\prime}\right), 7.16(1 \mathrm{H}, \mathrm{d}, J=16.2 \mathrm{~Hz}, \mathrm{H}-\alpha), 6.46(1 \mathrm{H}, \mathrm{s}, \mathrm{H}-$ 3); ${ }^{13} \mathrm{C} \mathrm{NMR}\left(\mathrm{CDCl}_{3}, 100 \mathrm{MHz}\right) \delta 177.1(\mathrm{C}-4), 162.88\left(\mathrm{~d}, J_{\mathrm{CF}}\right.$ $\left.=240.6 \mathrm{~Hz}, \mathrm{C} 4^{\prime}\right), 161.7$ (C-2), 155.4 (C-9), 135.4 (C- $\beta$ ), 134.4 (C-7), $131.6\left(\mathrm{~d}, J=3.2 \mathrm{~Hz}, \mathrm{C}-1^{\prime}\right), 130.0\left(\mathrm{~d}, J=8.1 \mathrm{~Hz}, \mathrm{C}-2^{\prime} / 6^{\prime}\right)$, 125.3 (C-6), 124.8 (C-5), 123.4 (C-10), 120.4 (C- $\alpha), 118.2$ (C-8), $116.0\left(\mathrm{~d}, J=24.3 \mathrm{~Hz}, \mathrm{C}-3^{\prime} / 5^{\prime}\right), 110.1(\mathrm{C}-3) ;{ }^{19} \mathrm{~F} \mathrm{NMR}\left(\mathrm{CDCl}_{3}\right.$, $376.5 \mathrm{MHz}) \delta-110.72$; EIMS $\left(m / z\right.$, rel. int.) $265\left(\mathrm{M}^{+}-1\right)(100)$, 
237 (8), 207 (13), 173 (10), 146 (39), 120 (18), 92 (20); HRMS $(m / z): 266.0721 \mathrm{M}^{+}$(calculated for $\mathrm{C}_{17} \mathrm{H}_{11} \mathrm{FO}_{2}: 266.0743$ ).

3',5'-Difluoro-2-styrylchromone (5d). Light brown solid residue $\left(92 \%\right.$ yield); mp $114-116^{\circ} \mathrm{C}$; $\mathrm{UV} \lambda_{\max }\left(\mathrm{CH}_{3} \mathrm{OH}\right) \mathrm{nm}$ $(\log \varepsilon) 322$ (3.49); IR (KBr) $v_{\max }: 1701(\mathrm{C}=\mathrm{O}), 1615,1586,1465$, 1390 (C-F), 1309, 1272, 1117 (C-F), 966, 847, $751 \mathrm{~cm}^{-1} ;{ }^{1} \mathrm{H}$ $\operatorname{NMR}\left(\mathrm{CDCl}_{3}, 400 \mathrm{MHz}\right) \delta 8.18(1 \mathrm{H}, \mathrm{dd}, J=7.9,1.6 \mathrm{~Hz}, \mathrm{H}-5)$, $7.72(1 \mathrm{H}$, ddd, $J=8.5,7.2,1.6 \mathrm{~Hz}, \mathrm{H}-7), 7.51(1 \mathrm{H}, \mathrm{d}, J=8.3 \mathrm{~Hz}$, $\mathrm{H}-8), 7.49(1 \mathrm{H}, \mathrm{d}, J=16.0 \mathrm{~Hz}, \mathrm{H}-\beta), 7.39(1 \mathrm{H}, \mathrm{td}, J=7.9$, $0.7 \mathrm{~Hz}, \mathrm{H}-6), 7.08\left(2 \mathrm{H}, \mathrm{dd}, J=8.1,1.9 \mathrm{~Hz}, \mathrm{H}-2^{\prime} / 6^{\prime}\right), 6.76(1 \mathrm{H}$, $\mathrm{d}, J=16.0 \mathrm{~Hz}, \mathrm{H}-\alpha), 6.81\left(1 \mathrm{H}, \mathrm{tt}, J=8.7,2.4 \mathrm{~Hz}, \mathrm{H}-4^{\prime}\right), 6.34$ $(1 \mathrm{H}, \mathrm{s}, \mathrm{H}-3) ;{ }^{13} \mathrm{C} \mathrm{NMR}\left(\mathrm{CDCl}_{3}, 100 \mathrm{MHz}\right) \delta 178.3$ (C-4), 163.4 $\left(\mathrm{dd}, J_{\mathrm{CF}}=247.8,12.9 \mathrm{~Hz}, \mathrm{C}^{\prime} / 5^{\prime}\right), 160.6(\mathrm{C}-2), 156.0(\mathrm{C}-9)$, $138.3\left(\mathrm{t}, J=11.2 \mathrm{~Hz}, \mathrm{C}-1^{\prime}\right), 134.0(\mathrm{C}-7), 134.2(\mathrm{t}, J=3.0 \mathrm{~Hz}$, C- $\beta$ ), 125.8 (C-5), 125.3 (C-6), 124.1 (C-10), 123.0 (C- $\alpha$ ), 117.9 $(\mathrm{C}-8), 111.7$ (C-3), $110.3\left(\mathrm{dd}, J=18.5,7.2 \mathrm{~Hz}, \mathrm{C}-2^{\prime} / 6^{\prime}\right), 105.0(\mathrm{t}$, $\left.J=25.4 \mathrm{~Hz}, \mathrm{C}-4^{\prime}\right) ;{ }^{19} \mathrm{~F} \mathrm{NMR}\left(\mathrm{CDCl}_{3}, 376.5 \mathrm{MHz}\right) \delta-109.31$; EIMS ( $m / z$, rel. int.) $284 \mathrm{M}^{+}(100), 267$ (82), 191 (40), 164 (63), 121 (58), 92 (65), 64 (21); HRMS (m/z): $284.0633 \mathrm{M}^{+}$ (calculated for $\mathrm{C}_{17} \mathrm{H}_{10} \mathrm{~F}_{2} \mathrm{O}_{2}: 284.0649$ ).

$7,4^{\prime}$-Difluoro-2-styrylchromone (5e). Pale yellow solid residue (45\% yield); mp $182-184^{\circ} \mathrm{C}$; UV $\lambda_{\max }\left(\mathrm{CH}_{3} \mathrm{OH}\right) \mathrm{nm}(\log \varepsilon)$ 322 (3.54); IR (KBr): $1659(\mathrm{C}=\mathrm{O}), 1621(\mathrm{C}=\mathrm{C}), 1598,1511$, 1438, 1377 (C-F), 1233, 1140, 1112, $967 \mathrm{~cm}^{-1} ;{ }^{1} \mathrm{H} \mathrm{NMR}\left(\mathrm{CDCl}_{3}\right.$, $400 \mathrm{MHz}) \delta 8.18(1 \mathrm{H}, \mathrm{dd}, J=8.8,6.4 \mathrm{~Hz}, \mathrm{H}-5), 7.56(2 \mathrm{H}, \mathrm{dd}$, $\left.J=8.6,5.6 \mathrm{~Hz}, \mathrm{H}-2^{\prime} / 6^{\prime}\right), 7.53(1 \mathrm{H}, \mathrm{d}, J=16.0 \mathrm{~Hz}, \mathrm{H}-\beta), 7.20$ $(1 \mathrm{H}, \mathrm{dd}, J=9.0,2.4 \mathrm{~Hz}, \mathrm{H}-8), 7.11-7.12(1 \mathrm{H}, \mathrm{m}, \mathrm{H}-6), 7.10(2 \mathrm{H}$, t, $\left.J=8.6 \mathrm{~Hz}, \mathrm{H}-3^{\prime} / 5^{\prime}\right), 6.67(1 \mathrm{H}, \mathrm{d}, J=16.0 \mathrm{~Hz}, \mathrm{H}-\alpha), 6.28(1 \mathrm{H}$, s, H-3); ${ }^{13} \mathrm{C} \mathrm{NMR}\left(\mathrm{CDCl}_{3}, 100 \mathrm{MHz}\right) \delta 177.4(\mathrm{C}-4), 167.1(\mathrm{~d}$, $\left.J_{\mathrm{CF}}=210.1 \mathrm{~Hz}, \mathrm{C}-7\right), 165.0\left(\mathrm{~d}, J_{\mathrm{CF}}=251.6 \mathrm{~Hz}, \mathrm{C}-4^{\prime}\right), 161.8(\mathrm{C}-$ 2), 156.9 (C-9), 135.8 (C- $\beta$ ), 131.2 (d, $\left.J=3.6 \mathrm{~Hz}, \mathrm{C}-1^{\prime}\right), 129.5$ $\left(\mathrm{d}, J=8.2 \mathrm{~Hz}, \mathrm{C}-2^{\prime} / 6^{\prime}\right), 128.2(\mathrm{~d}, J=10.5 \mathrm{~Hz}, \mathrm{C}-5), 121.0(\mathrm{C}-$ 10), $119.7(\mathrm{C}-\alpha), 116.2\left(\mathrm{~d}, J=21.9 \mathrm{~Hz}, \mathrm{C}-3^{\prime} / 5^{\prime}\right), 113.7$ (d, $J=$ $22.5 \mathrm{~Hz}, \mathrm{C}-6), 110.6$ (C-3), 104.6 (d, $J=25.5 \mathrm{~Hz}, \mathrm{C}-8) ;{ }^{19} \mathrm{~F} \mathrm{NMR}$ $\left(\mathrm{CDCl}_{3}, 376.5 \mathrm{MHz}\right) \delta-102.96,-109.89$; EIMS $(\mathrm{m} / z$, rel. int.) $283\left(\mathrm{M}^{+}-1\right)$ (100), 267 (56), 255 (8), 227 (13), 173 (13), 146 (50), 120 (10); HRMS ( $m / z): 284.0642$ (calculated for $\mathrm{C}_{17} \mathrm{H}_{10} \mathrm{~F}_{2} \mathrm{O}_{2}$ : 284.0649).

7-Fluoro-2-strychromone (5f). Off-white solid residue $(94 \%$ yield); mp $116-118^{\circ} \mathrm{C}$; UV $\lambda_{\max }\left(\mathrm{CH}_{3} \mathrm{OH}\right) \mathrm{nm}(\log \varepsilon) 312$ (3.35); IR (KBr) $v_{\max }: 1667$ (C=O), 1599, 1538, 1438, 1382 (CF stretch), 1143, 1012, $960 \mathrm{~cm}^{-1} ;{ }^{1} \mathrm{H} \mathrm{NMR}\left(\mathrm{CDCl}_{3}, 400 \mathrm{MHz}\right)$ $\delta 8.19(1 \mathrm{H}, \mathrm{dd}, J=8.9,6.4 \mathrm{~Hz}, \mathrm{H}-5), 7.59(1 \mathrm{H}, \mathrm{d}, J=16.0 \mathrm{~Hz}$, $\mathrm{H}-\beta), 7.58\left(2 \mathrm{H}, \mathrm{dd}, J=8.1,1.5 \mathrm{~Hz}, \mathrm{H}-2^{\prime} / 6^{\prime}\right), 7.39-7.41(3 \mathrm{H}, \mathrm{m}$, $\left.\mathrm{H}-3^{\prime} / 4^{\prime} / 5^{\prime}\right), 7.21(1 \mathrm{H}, \mathrm{dd}, J=9.1,2.4 \mathrm{~Hz}, \mathrm{H}-8), 7.10(1 \mathrm{H}, \mathrm{td}, J$ $=8.6,2.4 \mathrm{~Hz}, \mathrm{H}-6), 6.76(1 \mathrm{H}, \mathrm{d}, J=16.0 \mathrm{~Hz}, \mathrm{H}-\alpha), 6.29(1 \mathrm{H}$, s, H-3); ${ }^{13} \mathrm{C} \mathrm{NMR}\left(\mathrm{CDCl}_{3}, 100 \mathrm{MHz}\right) \delta 177.5(\mathrm{C}-4), 164.5$ (d, $\left.J_{\mathrm{CF}}=240.0 \mathrm{~Hz}, \mathrm{C}-7\right), 162.0(\mathrm{C}-2), 157.1(\mathrm{~d}, J=13.2 \mathrm{~Hz}, \mathrm{C}-9)$,

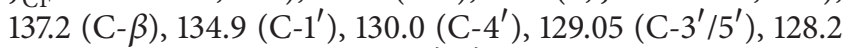
$(\mathrm{d}, J=10.6 \mathrm{~Hz}, \mathrm{C}-5), 127.7\left(\mathrm{C}-2^{\prime} / 6^{\prime}\right), 121.0(\mathrm{C}-10), 119.9(\mathrm{C}-\alpha)$, 113.7 (d, $J=22.6 \mathrm{~Hz}, \mathrm{C}-6), 110.6(\mathrm{C}-3), 104.6$ (d, $J=25.4 \mathrm{~Hz}$, C-8); ${ }^{19} \mathrm{~F} \mathrm{NMR}\left(\mathrm{CDCl}_{3}, 376.5 \mathrm{MHz}\right) \delta-103.04$; EIMS $(\mathrm{m} / z$, rel. int.) $265\left(\mathrm{M}^{+}-1\right)(100), 250$ (36), 237 (5), 209 (7), 128 (29), 102 (8); HRMS $(m / z): 266.0730$ (calculated for $\mathrm{C}_{17} \mathrm{H}_{11} \mathrm{FO}_{2}$ : 266.0743).
6-Fluoro-2-styrylchromone $(\mathbf{5 g})$. Light green solid residue (89\% yield); mp $108-110^{\circ} \mathrm{C}$; IR (KBr): $1710(\mathrm{C}=\mathrm{O}), 1628,1567$, $1478,1445,1378,1284,1172,967,818,751 \mathrm{~cm}^{-1} ;{ }^{1} \mathrm{H}$ NMR $\left(\mathrm{CDCl}_{3}, 400 \mathrm{MHz}\right) \delta 7.85(1 \mathrm{H}, \mathrm{dd}, J=8.2,3.2 \mathrm{~Hz}, \mathrm{H}-5), 7.60$ $(1 \mathrm{H}, \mathrm{d}, J=16.1 \mathrm{~Hz}, \mathrm{H}-\beta), 7.56\left(2 \mathrm{H}, \mathrm{d}, J=8.0 \mathrm{~Hz}, \mathrm{H}-2^{\prime} / 6^{\prime}\right)$, $7.52(1 \mathrm{H}, \mathrm{dd}, J=9.10,4.15 \mathrm{~Hz}, \mathrm{H}-8), 7.39-7.41(4 \mathrm{H}, \mathrm{m}, \mathrm{H}-$ $\left.3^{\prime} / 4^{\prime} / 5^{\prime} / 7\right), 6.77(1 \mathrm{H}, \mathrm{d}, J=16.1 \mathrm{~Hz}, \mathrm{H}-\alpha), 6.31(1 \mathrm{H}, \mathrm{s}, \mathrm{H}-3)$; ${ }^{13} \mathrm{C} \mathrm{NMR}\left(\mathrm{CDCl}_{3}, 100 \mathrm{MHz}\right) \delta 177.6(\mathrm{~d}, J=2.3 \mathrm{~Hz}, \mathrm{C}-4), 162.0$ $(\mathrm{C}-2), 159.5\left(\mathrm{~d}, J_{\mathrm{CF}}=245.1 \mathrm{~Hz}, \mathrm{C}-6\right), 152.20$ (C-9), 137.4 (C- $\beta$ ), $134.9\left(\mathrm{C}-1^{\prime}\right), 130.0\left(\mathrm{C}-4^{\prime}\right), 129.1\left(\mathrm{C}-3^{\prime} / 5^{\prime}\right), 127.7\left(\mathrm{C}-2^{\prime} / 6^{\prime}\right), 125.5$ (d, $J=7.1 \mathrm{~Hz}, \mathrm{C}-10), 121.8$ (d, $J=25.13 \mathrm{~Hz}, \mathrm{C}-7), 120.03$ (C-

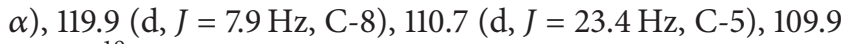
(C-3); ${ }^{19} \mathrm{~F} \mathrm{NMR}\left(\mathrm{CDCl}_{3}, 376.5 \mathrm{MHz}\right) \delta-115.51$; EIMS $(\mathrm{m} / z$, rel. int.) $265\left(\mathrm{M}^{+}-1\right)$ (100), 249 (43), 237 (9), 209 (12), 128 (56); calculated molecular mass: 266.67.

$4^{\prime}$-Methoxy-2-styrylchromone (5h). Yellow solid residue $(90 \%$ yield); mp 140-141 ${ }^{\circ} \mathrm{C}$ (lit. 139-140 [11]; UV $\lambda_{\max }\left(\mathrm{CH}_{3} \mathrm{OH}\right) \mathrm{nm}$ $(\log \varepsilon) 354$ (3.33); IR (KBr) $v_{\max }: 1645(\mathrm{C}=\mathrm{O}), 1599,1514,1462$, 462, 1258, 963, 828, $749 \mathrm{~cm}^{-1} ;{ }^{1} \mathrm{H}$ NMR $\left(\mathrm{CDCl}_{3}, 400 \mathrm{MHz}\right)$ $\delta 8.18(1 \mathrm{H}, \mathrm{dd}, J=8.0,1.6 \mathrm{~Hz}, \mathrm{H}-5), 7.65(1 \mathrm{H}, \mathrm{ddd}, J=8.6$, 7.1, 1.6 Hz, H-7), $7.55(1 \mathrm{H}, \mathrm{d}, J=16.0 \mathrm{~Hz}, \mathrm{H}-\beta), 7.52(1 \mathrm{H}, \mathrm{d}, J$ $=8.6 \mathrm{~Hz}, \mathrm{H}-8), 7.48\left(2 \mathrm{H}, \mathrm{d}, J=8.7 \mathrm{~Hz}, \mathrm{H}-2^{\prime} / 6^{\prime}\right), 7.36(1 \mathrm{H}, \mathrm{t}$, $J=8.0 \mathrm{~Hz}, \mathrm{H}-6), 6.92\left(2 \mathrm{H}, \mathrm{d}, J=8.7 \mathrm{~Hz}, \mathrm{H}-3^{\prime} / 5^{\prime}\right), 6.64(1 \mathrm{H}$, $\mathrm{d}, J=16.0 \mathrm{~Hz}, \mathrm{H}-\alpha), 6.28(1 \mathrm{H}, \mathrm{s}, \mathrm{H}-3), 3.84\left(3 \mathrm{H}, \mathrm{s}, \mathrm{OCH}_{3}\right)$; ${ }^{13} \mathrm{C} \mathrm{NMR}\left(\mathrm{CDCl}_{3}, 100 \mathrm{MHz}\right) \delta 178.5(\mathrm{C}-4), 162.3(\mathrm{C}-2), 161.1$ $\left(\mathrm{C}-4^{\prime}\right), 156.0(\mathrm{C}-9), 136.7(\mathrm{C}-\beta), 133.6(\mathrm{C}-7), 131.0\left(\mathrm{C}-1^{\prime}\right), 129.3$ $\left(\mathrm{C}-2^{\prime} / 6^{\prime}\right), 125.7$ (C-5), 124.9 (C-6), 124.2 (C-10), 117.90 (C- $\left.\alpha\right)$, 117.85 (C-8), $114.5\left(\mathrm{C}-3^{\prime} / 5^{\prime}\right), 109.9$ (C-3), $55.4\left(\mathrm{OCH}_{3}\right)$; EIMS $\left(\mathrm{m} / z\right.$, rel. int.) $277\left(\mathrm{M}^{+}-1\right)(100), 247(21), 207(\overline{19}), 158(38)$, 115 (55); calculated molecular mass: 278.30 .

$3^{\prime}, 4^{\prime}$-Dimethoxy-2-styrylchromone (5i). Yellow solid residue (55\% yield); mp $162-163^{\circ} \mathrm{C}$ (lit. $163-164^{\circ} \mathrm{C}$ [11]); UV $\lambda_{\max }$ $\left(\mathrm{CH}_{3} \mathrm{OH}\right) \mathrm{nm}(\log \varepsilon) 367$ (3.18); IR (KBr) $v_{\max }: 1682(\mathrm{C}=\mathrm{O})$, $1617,1558,1509,1464,1381,1261,1138,1025,965,780,759 \mathrm{~cm}^{-1}$; ${ }^{1} \mathrm{H}$ NMR $\left(\mathrm{CDCl}_{3}, 400 \mathrm{MHz}\right) \delta 8.01(1 \mathrm{H}, \mathrm{dd}, J=7.9,1.7 \mathrm{~Hz}$, H-5), 7.81 (1H, ddd, $J=8.2,7.2,1.7 \mathrm{~Hz}, \mathrm{H}-7), 7.70(1 \mathrm{H}, \mathrm{d}, J=$ $8.2 \mathrm{~Hz}, \mathrm{H}-8), 7.65(1 \mathrm{H}, \mathrm{d}, J=16.0 \mathrm{~Hz}, \mathrm{H}-\beta), 7.47(1 \mathrm{H}$, ddd, $J=$ 7.9, 7.2, $0.7 \mathrm{~Hz}, \mathrm{H}-6), 7.36\left(1 \mathrm{H}, \mathrm{d}, J=1.7 \mathrm{~Hz}, \mathrm{H}-2^{\prime}\right), 7.27(1 \mathrm{H}, \mathrm{dd}$, $\left.J=8.3,1.7 \mathrm{~Hz}, \mathrm{H}-6^{\prime}\right), 7.11(1 \mathrm{H}, \mathrm{d}, J=16.0 \mathrm{~Hz}, \mathrm{H}-\alpha), 7.02(1 \mathrm{H}, \mathrm{d}, J$ $\left.=8.3 \mathrm{~Hz}, \mathrm{H}-5^{\prime}\right), 6.40(1 \mathrm{H}, \mathrm{s}, \mathrm{H}-3), 3.80\left(3 \mathrm{H}, \mathrm{s}, 3^{\prime}-\mathrm{OCH}_{3}\right), 3.83$ $\left(\mathrm{s}, 3 \mathrm{H}, 4^{\prime}-\mathrm{OCH}_{3}\right) ;{ }^{13} \mathrm{C} \mathrm{NMR}\left(\mathrm{CDCl}_{3}, 100 \mathrm{MHz}\right) \delta 177.0(\mathrm{C}-4)$, 162.3 (C-2), 155.4 (C-9), $150.5\left(\mathrm{C}-4^{\prime}\right), 149.0\left(\mathrm{C}-3^{\prime}\right), 136.9(\mathrm{C}-\beta)$, 134.2 (C-7), $127.8\left(\mathrm{C}-1^{\prime}\right), 125.2$ (C-6), 124.7 (C-5), 123.4 (C-10), $122.3\left(\mathrm{C}-6^{\prime}\right), 118.1(\mathrm{C}-8), 118.0(\mathrm{C}-\alpha), 111.7\left(\mathrm{C}-5^{\prime}\right), 109.9\left(\mathrm{C}-2^{\prime}\right)$, $109.2(\mathrm{C}-3), 55.5\left(2 \times \mathrm{OCH}_{3}\right)$; EIMS $\left(\mathrm{m} / z\right.$, rel. int.) $308\left(\mathrm{M}^{+}\right)$ (100), 277 (22), 250 (10), 221 (14), 188 (70), 121 (19); calculated molecular mass: 308.33 .

$3^{\prime}, 4^{\prime}$-Methylenedioxy-2-styrylchromone (5j). Yellow solid residue (92\% yield); mp $209-210^{\circ} \mathrm{C}$ (lit. $209-210^{\circ} \mathrm{C}$ [11]); UV $\lambda_{\text {max }}\left(\mathrm{CH}_{3} \mathrm{OH}\right) \mathrm{nm}(\log \varepsilon) 329$ (3.36); IR (KBr) $v_{\max }: 1694$ (C=O), 1625, 1461, 1499, 1447, 1383, 1251, $845 \mathrm{~cm}^{-1}$; ${ }^{1} \mathrm{H}$ NMR $\left(\mathrm{CDCl}_{3}, 400 \mathrm{MHz}\right) \delta 8.17(1 \mathrm{H}, \mathrm{d}, J=7.6 \mathrm{~Hz}, \mathrm{H}-5), 7.65(1 \mathrm{H}$, ddd, $J=8.1,7.1,1.0 \mathrm{~Hz}, \mathrm{H}-7), 7.51(1 \mathrm{H}, \mathrm{d}, J=7.8 \mathrm{~Hz}, \mathrm{H}-8)$, $7.50(1 \mathrm{H}, \mathrm{d}, J=16.1 \mathrm{~Hz}, \mathrm{H}-\beta), 7.37(1 \mathrm{H}, \mathrm{t}, J=7.5, \mathrm{H}-6), 7.08$ $\left(1 \mathrm{H}, \mathrm{s}, \mathrm{H}-2^{\prime}\right), 7.05\left(1 \mathrm{H}, \mathrm{d}, J=8.1 \mathrm{~Hz}, \mathrm{H}-6^{\prime}\right), 6.81(1 \mathrm{H}, \mathrm{d}$, 
$\left.J=8.1 \mathrm{~Hz}, \mathrm{H}-5^{\prime}\right), 6.59(1 \mathrm{H}, \mathrm{d}, J=16.1, \mathrm{H}-\alpha), 6.28(1 \mathrm{H}, \mathrm{s}, \mathrm{H}-3)$, $6.01\left(2 \mathrm{H}, \mathrm{s}, \mathrm{OCH}_{2} \mathrm{O}\right) ;{ }^{13} \mathrm{C} \mathrm{NMR}\left(\mathrm{CDCl}_{3}, 100 \mathrm{MHz}\right) \delta 178.5$ (C-4), 162.0 (C-2), 156.0 (C-9), 149.3 (C-3'), 148.5 (C-4'), 136.7 (C- $\beta$ ), 133.7 (C-7), 129.5 (C-1'), 125.7 (C-5), 125.0 (C-6), $123.9\left(\mathrm{C}-6^{\prime}\right), 123.3(\mathrm{C}-10), 118.4(\mathrm{C}-\alpha), 117.8(\mathrm{C}-8), 110.2(\mathrm{C}-3)$, $108.7\left(\mathrm{C}-5^{\prime}\right), 106.2\left(\mathrm{C}-2^{\prime}\right), 101.6\left(\mathrm{OCH}_{2} \mathrm{O}\right)$; EIMS $(\mathrm{m} / z$, rel. int.) $291\left(\mathrm{M}^{+}-1\right)(100), 275$ (55), 233 (18), 205 (24), 172 (67), 114 (29); calculated molecular mass: 292.29 .

2.6. X-Ray Crystallographic Study. Single-crystal X-ray diffraction data were collected on a Bruker KAPPA APEX II DUO diffractometer using graphite-monochromated Mo-K $\alpha$ radiation $(\chi=0.71073 \AA)$. Data collection was carried out at 173(2) K. Temperature was controlled by an Oxford Cryostream cooling system (Oxford Cryostat). Cell refinement and data reduction were performed using the program SAINT [39]. The data were scaled, and absorption correction was performed using SADABS [40]. The structure was solved by direct methods using SHELXS-97 [40] and refined by full-matrix least-squares methods based on $F^{2}$ using SHELXL-97 [40] and using the graphics interface program X-Seed [41, 42]. The programs X-Seed and POVRay were both used to prepare molecular graphic images. All nonhydrogen atoms were refined anisotropically, and all hydrogen atoms could be found in the difference electron density maps but were placed in idealised positions and refined in riding models with $\mathrm{U}_{\text {iso }}$ set at 1.2 times those of their parent atoms and at a distance $(\mathrm{C}-\mathrm{H})$ of $0.95 \AA$. The structure was refined to a $R$ factor of 0.0503 .

CCDC 897969 contains the supplementary crystallographic data for this paper. These data can be obtained free of charge via http://www.ccdc.cam.ac.uk/conts/retrieving.html (or from the CCDC, 12 Union Road, Cambridge CB2 1EZ, UK; fax: +44 1223 336033; e-mail: deposit@ccdc.cam.ac.uk).

2.7. Antibacterial Assay. In vitro evaluation of antibacterial activity was carried out on all synthesized, fluorinated, and oxygenated 2-styrylchromones by the disc diffusion method as described by Bauer et al. [43] against the Gram-positive bacteria, Bacillus subtilis, Enterococcus faecium, and three Staphylococcus species, aureus, sciuri, and xylosus, and the Gram-negative bacteria, Escherichia coli, Klebsiella pneumoniae, and Pseudomonas aeruginosa. The standard antibiotics, tetracycline (Te) and ampicillin (Amp), were used as controls and for comparison. Briefly, Mueller Hilton agar was prepared (38 g in $1 \mathrm{~L}$ of water) and poured into prelabeled sterile Petri dishes, which were then allowed to set and dry at room temperature. The bacterial organisms were standardized using a $0.5 \mathrm{McF}$ arland standard turbidity and then swabbed onto the agar plates. Paper discs with dissolved sample and a control disc was placed onto the agar plates, which were inverted and incubated at $35-37^{\circ} \mathrm{C}$ for 24 hours. The diameter of the inhibition zones were then measured in $\mathrm{mm}$. The tests were done in triplicate, and the results were reported as means of at least three determinations. The results are summarized in Tables 2 and 3.

The activity index of the product 2-styrylchromones was calculated as follows: Activity index (A.I.) = zone of inhibition of compound/Zone of inhibition obtained for the standard antibiotic drug.

\section{Results and Discussion}

3.1. Chemistry. Seven fluorinated 2-styrylchromones of which six (5a-f) were novel were prepared in good overall yields of between 60 and $90 \%$ with only one compound (5e) having a yield of $45 \%$. The synthesis was carried out according to the three-step sequence shown in Figure 1 and based on the Baker-Venkataraman rearrangement [16]. This involved the formation of the desired $2^{\prime}$-cinnamoyloxyacetophenones from substituted ortho-hydroxyacetophenones and cinnamic acid derivatives in pyridine using $\mathrm{POCl}_{3}$ as a condensing agent. A strong base such as potassium hydroxide abstracts a proton from the methyl ketone, and the resultant carbanion attacks the ester carbonyl resulting in the conversion of the cinnamoyloxyacetophenones to the ketoenols. A ring chain tautomerism then occurs in this intermediate which is subsequently protonated by the strong catalyst para-toluene sulfonic acid, and attack by the $2^{\prime}$-hydroxy group ultimately results in the more stable chromone product by elimination. The cinnamic acids, $\mathbf{2 a}-\mathbf{c}$ and $\mathbf{2 h}-\mathbf{I}$, were prepared by an aldol condensation and elimination reaction from the corresponding benzaldehydes and malonic acid before being reacted with the corresponding acetophenones.

The series of 2-styrylchromones synthesized contained a single fluorine atom on the ortho-, meta-, and para-positions $(5 \mathbf{a}-\mathbf{c})$ of the phenyl ring, two fluorine atoms at the $3^{\prime}$ and $5^{\prime}$ positions on the phenyl ring (5d), fluorine atoms on both of the aromatic rings (at the 7 and $4^{\prime}$ positions) (5e), and a single fluorine atom on the $6(5 \mathbf{f})$ and $7(5 \mathbf{g})$ positions on the chromone ring. These substitution patterns were chosen to observe the effect of fluorine at different positions on the phenyl ring as well as the effect of fluorine on the chromone ring. The difluorinated compounds would provide information on multiple sites of the molecule as well as substitution on both the phenyl and chromone rings simultaneously. Two methoxylated 2-styrylchromones, the $4^{\prime}$-methoxy- and the $3^{\prime}, 4^{\prime}$-dimethoxy-2-styrylchromones as well as the $3^{\prime}, 4^{\prime}$-methylenedioxy-2-styrylchromone $(\mathbf{5} \mathbf{h}-\mathbf{j})$ were also synthesized to test alongside the fluorinated styrylchromones for comparison.

The structures of the prepared compounds were elucidated using $1 \mathrm{D}$ and 2D NMR spectroscopies along with mass spectrometry and IR spectroscopy. Compounds $\mathbf{5} \mathbf{g}-\mathbf{j}$ and their intermediates were all prepared previously [11, 27]; however only the NMR data for $\mathbf{4 g}$ and $\mathbf{5 g}$ [27], $3 \mathrm{~h}$ and $\mathbf{4 h}$ [20] and $\mathbf{3 i}$ and $4 \mathbf{i}$ [37] is available in the literature. Furthermore, only the ${ }^{1} \mathrm{H}$ NMR data is given for $\mathbf{5 g}$ [27], and only the ethylene resonance is reported for $\mathbf{5 h}-\mathbf{j}$ [11]. The NMR data for $\mathbf{3 g}, \mathbf{3} \mathbf{j}, \mathbf{4 j}$, and $\mathbf{5 g}-\mathbf{j}$ is therefore also reported here along with the new compounds $\mathbf{5} \mathbf{a}-\mathbf{f}$ and their intermediates $\mathbf{3 a}-\mathbf{f}$ and $4 \mathbf{a}-\mathbf{f}$, to provide a complete set of NMR data for all the synthesized 2-styrylchromones and their intermediates.

The cinnamoyloxyacetophenone (3a) was established by the presence of $\alpha$ and $\beta$ unsaturated proton resonances in the ${ }^{1} \mathrm{H}$ NMR spectrum at $\delta_{\mathrm{H}} 6.76$ and 8.00 as two doublets 
with large coupling constants of $16.2 \mathrm{~Hz}$, typical of trans olefinic protons, a methyl singlet at $\delta_{\mathrm{H}} 2.55$, and aromatic protons between $\delta_{\mathrm{H}} 7.11$ and 7.85. The structure of $3 \mathrm{a}$ was further supported by two carbonyl resonances in the ${ }^{13} \mathrm{C}$ NMR spectrum at $\delta_{\mathrm{C}} 197.7$ for the ketone and $\delta_{\mathrm{C}} 165.1$ for the ester carbonyl. The aromatic carbon to which fluorine was attached was detected at $\delta_{\mathrm{C}} 161.8(J=252.6 \mathrm{~Hz})$. The fluorine NMR resonance at $\delta-113.57$ was used to confirm the presence of fluorine on the aromatic ring, and the structure was confirmed by the detection of the molecular ion at $\mathrm{m} / z$ 284 in the EIMS. The other intermediates $\mathbf{3 b} \mathbf{b}-\mathbf{j}$ had similar NMR data, and the structures were elucidated in the same manner as 3a. The aromatic oxygenated carbon resonance in $3 \mathrm{~h}$ was recorded at $\delta_{\mathrm{C}} 161.91$ with similar resonances occurring in $\mathbf{3 i} \mathbf{i} \mathbf{j}$.

Conversion to the ketoenol (4a) was indicated by the disappearance of the methyl singlet resonance and the appearance of a singlet proton resonance at $\delta_{\mathrm{H}} 6.32$ for the olefinic $\alpha$ proton. This was supported by the enol carbon resonance at approximately $\delta_{\mathrm{C}} 173.6$ and the keto resonance at $\delta_{\mathrm{C}} 196.3$. The fluorinated carbon resonance could be seen at $\delta_{\mathrm{C}} 164.9$ with a coupling constant of $247.2 \mathrm{~Hz}$ and the olefinic $\mathrm{C}-\mathrm{O}$ resonance at $\delta_{\mathrm{C}}$ 162.7. The ${ }^{19} \mathrm{~F}$ NMR resonance at $\delta-112.32$ and the molecular ion at $m / z 284$ in the MS spectrum further confirmed the structure. The other intermediates, $\mathbf{4 b} \mathbf{b} \mathbf{j}$, were elucidated in a similar manner.

Cyclisation to the 2-styrylchromones was indicated by a marked shift in the H-5 resonance from $\delta_{\mathrm{H}} 7.69$ in $\mathbf{4 a}$ to $\delta_{\mathrm{H}}$ 8.17 in 5a. Further to this, only a single pyran carbonyl resonance could be seen at $\delta_{\mathrm{C}} 178.4$ in the ${ }^{13} \mathrm{C}$ NMR spectrum. The C-2 resonance was evident at $\delta_{\mathrm{C}} 161.5$ and the doublet CF resonance at $161.2(J=253.3)$, which was supported by the ${ }^{19} \mathrm{~F}$ NMR resonance at $\delta-115.39$. The structures of $\mathbf{5 b} \mathbf{b}-\mathbf{j}$ were confirmed similarly. All intermediates and final products were further confirmed by 2D NMR spectroscopy and by the presence of the molecular ion using mass spectrometry.

In addition, the crystal structure of 5a was carried out to determine the extent to which the molecule was planar. As can be seen in Figure 2 and from the data in Table 1, the molecule is almost planar with bond angles between 116 and $124^{\circ}$. The compound crystallizes with four planar molecules in the symmetric unit and contains four molecules per unit cell. The molecule has a $\mathrm{C}-\mathrm{F}$ bond distance of $1.336 \AA$ and a $\mathrm{C}=\mathrm{O}$ distance of $1.237 \AA$ (Table 2 ). The fluorine atom is $0.392 \AA$ from the plane, and the $\mathrm{H} \alpha$ and $\mathrm{H} \beta$ hydrogen atoms are 0.958 and $1.082 \AA$ from the plane, respectively.

3.2. Antibacterial Activity. The fluorinated derivatives (5a-g) were most effective against Gram-positive bacteria, particularly B. subtilis and S. aureus, with that against B. subtilis being more predominant (Table 2 ). The two methoxy derivatives (5h and $5 \mathbf{i}$ ) were only effective against $B$. subtilis, with the dimethoxy derivative (5i) also being active against a strain of S. aureus (ATCC 29212), while the dioxole derivative (5j) displayed no antibacterial activity against both Gramnegative and Gram-positive bacteria. Thus, in comparing the methoxy (5h-i) and fluoro derivatives $(\mathbf{5} \mathbf{a}-\mathbf{g})$, the fluoro derivatives were far superior in their activity to the methoxy

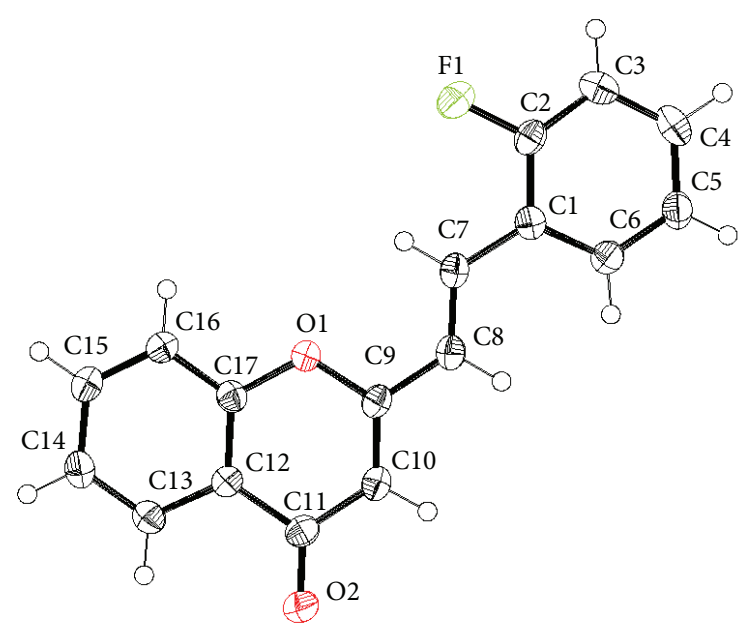

FIGURE 2: ORTEP diagram of a crystal of $2 '$-fluoro-2-styrylchromone at $50 \%$ probability level.

TABLE 1: Selected bond angles and bond lengths of $2^{\prime}$-fluorostyrylchromone.

\begin{tabular}{lcccccc}
\hline No. & Atom1 & Atom2 & Atom3 & Angle & Atoms & Length \\
\hline 1 & C17 & O1 & C9 & $118.7(2)$ & C2-F1 & 1.366 \\
2 & F1 & C2 & C1 & $117.4(2)$ & C9-O1 & 1.369 \\
3 & C3 & C2 & F1 & $118.1(2)$ & C11-O2 & 1.237 \\
4 & C10 & C11 & O2 & $123.9(2)$ & C17-O1 & 1.384 \\
5 & C12 & C11 & O2 & $122.4(2)$ & C7-C8 & 1.335 \\
6 & O1 & C17 & C12 & $121.8(2)$ & C7-C1 & 1.460 \\
7 & O1 & C17 & C16 & $116.1(2)$ & C8-C9 & 1.448 \\
\hline
\end{tabular}

compounds. Limited antibacterial activity was observed with Gram-negative bacteria (Table 2), with K. pneumoniae and $P$. aeruginosa being completely resistant to all the tested compounds. Although the addition of fluorine to the benzene ring resulted in antibacterial action against E. coli ATCC 25922, it was not effective against the E. coli ATCC 35218 strain (Table 2 ) and the activity appeared to be strain-specific. The difluorinated styrylchromones showed a broader spectrum, with only $\mathbf{5 d}$ and $\mathbf{5 e}$ being effective against both $E$. coli strains tested (Table 2), indicating that multiple fluorinations on the 2-styrylchromone backbone could lead to enhanced activity against E. coli. However, fluorination on the chromone ring only resulted in no activity against $E$. coli.

The $3^{\prime}, 5^{\prime}$ derivative (5d) showed the greatest activity from all the compounds substituted on the phenyl ring. This compound also showed activity against both E. coli strains tested. This could therefore indicate that the activity of the 2-styrylchromones increases with increased fluorine substitution on the phenyl ring. Fluorination at position 7 on the chromone ring resulted in the compound being active against $B$. subtilis alone. This activity increased slightly with additional fluorine substitution at the $4^{\prime}$ position, as activity was now experienced with $S$. sciuri and both the E. coli strains with 5e. However, both compounds with fluorine substitution at position 7 did not show activity 


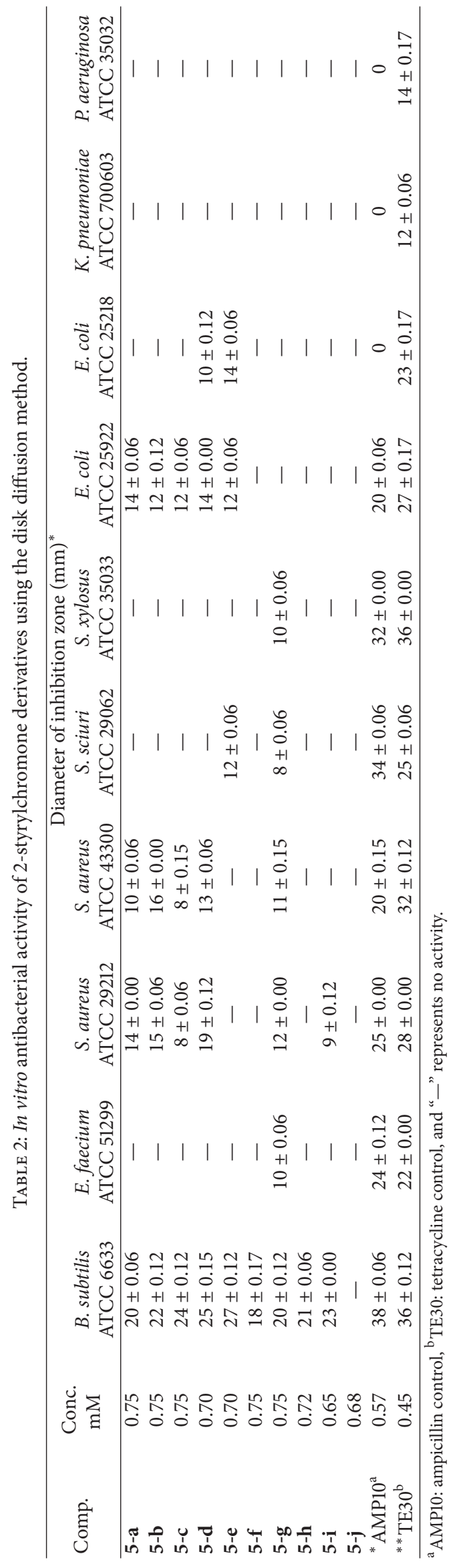




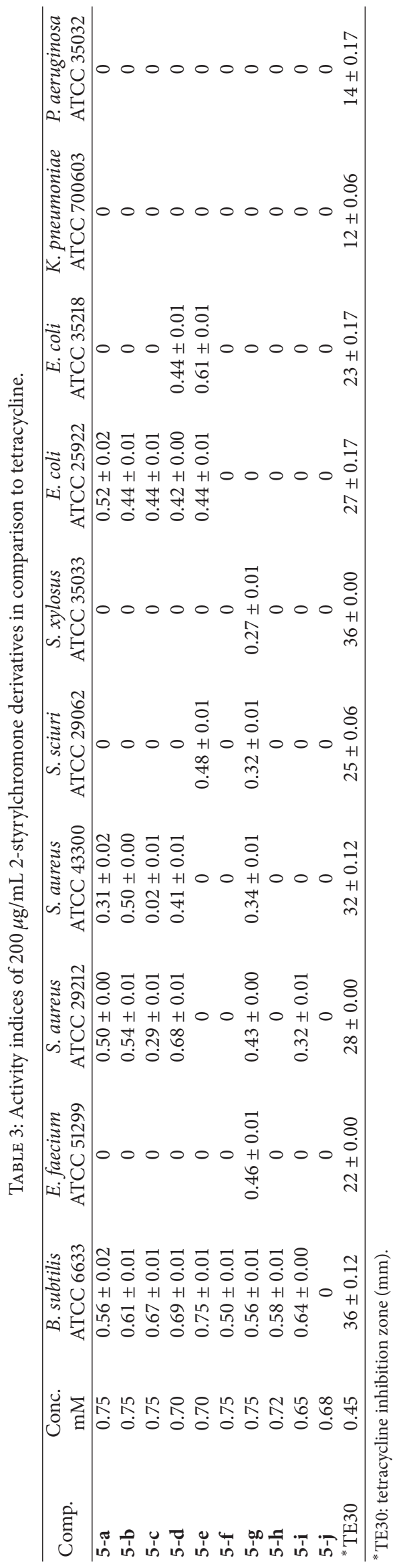


against $S$. aureus. In contrast, the $5 \mathrm{~g}$ derivative, with fluorine at position 6 of the chromone ring, was the most effective of all the tested compounds, with an observable inhibitory effect against $100 \%$ of the Gram-positive bacteria (Table 2). In fact, it was the only compound that showed any activity against E. faecium. This compound however did not show any activity to any of the Gram-negative bacteria. In another study, the $\mathbf{5 g}$ derivative (6-fluorinated) also showed antirhinovirus activity by interfering with the replication of the HRV serotype 14 and serotype $1 \mathrm{~B}$ [27].

Although an activity index of greater than or equal to 1 relative to tetracycline susceptibility is ideal, in the present study activity indices ranged from 0 (no activity) to 0.75 (Table 3 ). Activity indices ranging from $0.27-0.56$ were obtained following testing of the 6-F derivative $(5 \mathrm{~g})$ against Gram-positive bacteria. Gram-positive organisms appeared to be more susceptible to the fluorine and methoxy derivatives compared to Gram-negative bacteria.

This may be related to their mode of antimicrobial action, which remains to be elucidated. The low activity indices do not preclude the use of these derivatives with antibacterial activity, and these compounds may have the potential to be used as mild antibiotics.

\section{Conclusion}

Several new fluorinated 2-styrylchromones (5a-5f) were synthesized along with a known fluorinated compound (5g), two methoxylated compounds (5h-i), and a methylenedioxy derivative $(\mathbf{5 j})$. The compounds were characterized and screened for their antibacterial activity. In general, the fluorinated compounds displayed antibacterial activity against Gram-positive bacteria more than Gram-negative bacteria, with the fluorinated styrylchromones being most active against $B$. subtilis followed by $S$. aureus and then a single strain of E. coli (ATCC 25922), but not the E. coli (ATCC 35218) strain, indicating that their activity toward E. coli is strain specific. However, the styrylchromones with two fluorine substitutions showed activity against both $E$. coli strains, indicating that a broader spectrum could be obtained with multiple fluorinations on the styrylchromone backbone. Furthermore, the $3^{\prime}, 5^{\prime}$-difluorostyrylchromone (5d) showed the best activity from all the compounds fluorinated on the phenyl ring, also indicating that more fluorine substitutions on the styrylchromone could lead to enhanced activity.

Activity of the styrylchromones substituted on the chromone ring was specific to fluorination at position 6 , which showed the best activity amongst all the compounds tested. Fluorination at position 7 was only active against one bacterial strain, B. subtilis. Thus, the position and number of fluorine substituents on either the phenyl or the chromone ring have an effect on the antibacterial activity of the 2styrylchromones. It is worthwhile exploring the effect of hydroxy, methoxy, and fluorine substitutions on the phenyl ring together with fluorine substitution at position 6 , as these compounds may show enhanced activity.

\section{Conflict of Interests}

The authors declare that they do not have any financial relations with any of the commercial entities mentioned in the paper that could lead to a conflict of interests.

\section{Acknowledgments}

This research was supported by grants from the National Research Foundation (NRF), South Africa, and was supported by the South African Research Chairs Initiative of the Department of Science and Technology.

\section{References}

[1] B. K. Park, N. R. Kitteringham, and P. M. O’Neill, "Metabolism of fluorine-containing drugs," Annual Review of Pharmacology and Toxicology, vol. 41, pp. 443-470, 2001.

[2] K. L. Kirk and R. Filler, "Recent advances in the biomedicinal chemistry of fluorine-containing compounds," in Biomedical Frontiers of Fluorine Chemistry, I. Ojima, J. R. McCarthy, and T. Welch, Eds., vol. 639 of Symposium Series, pp. 1-24, American Chemical Society, Washington, DC, USA, 1996.

[3] D. O'Hagan and H. S. Rzepa, "Some influences of fluorine in bioorganic chemistry," Chemical Communications, no. 7, pp. 645-652, 1997.

[4] A. Gomes, M. Freitas, E. Fernandes, and J. L. F. C. Lima, "Biological activities of 2-styrylchromones," Mini-Reviews in Medicinal Chemistry, vol. 10, no. 1, pp. 1-7, 2010.

[5] Y. Karton, J.-L. Jiang, X.-D. Ji et al., "Synthesis and biological activities of flavonoid derivatives as $\mathrm{A}_{3}$ adenosine receptor antagonists," Journal of Medicinal Chemistry, vol. 39, no. 12, pp. 2293-2301, 1996.

[6] E. Fernandes, M. Carvalho, F. Carvalho et al., "Hepatoprotective activity of polyhydroxylated 2-styrylchromones against tertbutylhydroperoxide induced toxicity in freshly isolated rat hepatocytes," Archives of Toxicology, vol. 77, no. 9, pp. 500-505, 2003.

[7] P. Filipe, A. M. S. Silva, P. Morlière et al., "Polyhydroxylated 2styrylchromones as potent antioxidants," Biochemical Pharmacology, vol. 67, no. 12, pp. 2207-2218, 2004.

[8] G. Doria, C. Romeo, and A. Forgione, "Antiallergic agents. III. Substituted trans-2-etheneyl-4-oxo-4H-1-benzopyran-6carboxylic acids," European Journal of Medicinal Chemistry, vol. 14, no. 4, pp. 347-351, 1979.

[9] N. Desideri, C. Conti, P. Mastromarino, and F. Mastropaolo, "Synthesis and anti-rhinovirus activity of 2-styrylchromones," Antiviral Chemistry and Chemotherapy, vol. 11, no. 6, pp. 373381, 2000.

[10] J. Marinho, M. Pedro, D. C. G. A. Pinto et al., " 4 '-Methoxy2-styrylchromone a novel microtubule-stabilizing antimitotic agent," Biochemical Pharmacology, vol. 75, no. 4, pp. 826-835, 2008.

[11] K. Momoi, Y. Sugita, M. Ishihara et al., "Cytotoxic activity of styrylchromones against human tumor cell lines," In Vivo, vol. 19, no. 1, pp. 157-164, 2005.

[12] W. H. Gerwick, "Cytotoxic substances from the marine cyanophyte Hormothamnion enteromorphoides Grunow," European patent 237166, 1987. 
[13] E. Fernandes, F. Carvalho, A. M. S. Silva et al., "2-Styrylchromones as novel inhibitors of xanthine oxidase. A structureactivity study," Journal of Enzyme Inhibition and Medicinal Chemistry, vol. 17, no. 1, pp. 45-48, 2002.

[14] A. M. S. Silva, D. C. G. A. Pinto, J. A. S. Cavaleiro, A. Levai, and T. Patonay, "Synthesis and reactivity of styrylchromones," Arkivoc, vol. 2004, no. 7, pp. 106-123, 2004.

[15] A. M. S. Silva, D. C. G. A. Pinto, H. R. Tavares, J. A. S. Cavaleiro, M. L. Jimeno, and J. Elguero, "Novel $(E)$ - and $(Z)-$ 2-styrylchromones from $(E, E)-2^{\prime}$-hydroxycinnamylideneacetophenones-xanthones from daylight photooxidative cyclization of (E)-2-styrylchromones," European Journal of Organic Chemistry, no. 9, pp. 2031-2038, 1998.

[16] D. C. G. A. Pinto, A. M. S. Silva, and J. A. S. Cavaleiro, "A convenient synthesis of new $(E)$-5-hydroxy-2-styrylchromones by modifications of the Baker-Venkataraman method," New Journal of Chemistry, vol. 24, no. 2, pp. 85-92, 2000.

[17] B. P. Reddy and G. L. David Krupadanam, "The synthesis of 8allyl-2-styrylchromones by the modified Baker-Venkataraman transformation," Journal of Heterocyclic Chemistry, vol. 33, no. 6, pp. 1561-1565, 1996.

[18] D. C. G. A. Pinto, A. M. S. Silva, C. M. Brito et al., "Reactivity of 3-styrylchromones as dienes in Diels-Alder reactions under microwave irradiation: a new synthesis of xanthones," European Journal of Organic Chemistry, no. 14, pp. 2973-2986, 2005.

[19] A. M. S. Silva, A. M. G. Silva, A. C. Tomé, and J. A. S. Cavaleiro, "New syntheses of flavones from Diels-Alder reactions of 2- styrylchromones with ortho-benzoquinodimethanes," European Journal of Organic Chemistry, no. 1, pp. 135-139, 1999.

[20] D. C. G. A. Pinto, A. M. S. Silva, L. M. P. M. Almeida, J. A. S. Cavaleiro, A. Lévai, and T. Patonay, "Synthesis of 4-aryl-3-(2chromonyl)-2-pyrazolines by the 1,3-dipolar cycloaddition of 2-styrylchromones with diazomethane," Journal of Heterocyclic Chemistry, vol. 35, no. 1, pp. 217-224, 1998.

[21] G. Toth, A. Levai, A. Szollosy, and H. Duddeck, "Synthesis and conformational analysis of some spiropyrazoline isomers," Tetrahedron, vol. 49, no. 4, pp. 863-880, 1993.

[22] A. M. S. Silva, J. S. Vieira, J. A. S. Cavaleiro, T. Patonay, A. Lévai, and J. Elguero, "New syntheses of 4(5)-aryl-5(4)-(2chromonyl)-1,2,3-triazoles from 2- styrylchromones and sodium azide," Heterocycles, vol. 51, no. 3, pp. 481-487, 1999.

[23] K. Takagi, M. Tanaka, and T. Murakami, "Synthesis of new 3(5)(2-hydroxyphenyl)pyrazoles as potential analgesic agents and platelet aggregation inhibitors," European Journal of Medicinal Chemistry, vol. 21, no. 1, pp. 65-69, 1986.

[24] D. C. G. A. Pinto, A. M. S. Silva, and J. A. S. Cavaleiro, "Novel (E)-3-(2' -benzyloxy-6' -hydroxyphenyl)-5-styrylpyrazoles from (E)-2-styrylchromones," Heterocyclic Communications, vol. 3, no. 5, pp. 433-436, 1997.

[25] D. C. G. A. Pinto, A. M. S. Silva, and J. A. S. Cavaleiro, "Synthesis of 3-(2-benzyloxy-6-hydroxyphenyl)-1-methylpyrazoles by the reaction of chromones with methylhydrazine," Journal of Heterocyclic Chemistry, vol. 37, no. 6, pp. 1629-1634, 2000.

[26] B. K. Karale, C. H. Gill, and M. S. Shingare, "Synthesis of styrylpyrimidines," Indian Journal of Heterocyclic Chemistry, vol. 12, no. 3, pp. 267-270, 2003.

[27] C. Conti, P. Mastromarino, P. Goldoni, G. Portalone, and N. Desideri, "Synthesis and anti-rhinovirus properties of fluorosubstituted flavonoids," Antiviral Chemistry and Chemotherapy, vol. 16, no. 4, pp. 267-276, 2005.

[28] A. Y. Shaw, C.-Y. Chang, H.-H. Liau et al., "Synthesis of 2-styrylchromones as a novel class of antiproliferative agents targeting carcinoma cells," European Journal of Medicinal Chemistry, vol. 44, no. 6, pp. 2552-2562, 2009.

[29] Y. Qian, H.-J. Zhang, H. Zhang, C. Xu, J. Zhao, and H.-L. Zhu, "Synthesis, molecular modeling, and biological evaluation of cinnamic acid metronidazole ester derivatives as novel anticancer agents," Bioorganic and Medicinal Chemistry, vol. 18, no. 14, pp. 4991-4996, 2010.

[30] W. F. Bailey and S. C. Longstaff, "Generation and cyclization of a benzyne-tethered alkyllithium: preparation of 4-substituted indans," Journal of Organic Chemistry, vol. 63, no. 3, pp. 432433, 1998.

[31] W. Szymanski, B. Wu, B. Weiner, S. De Wildeman, B. L. Feringa, and D. B. Janssen, "Phenylalanine aminomutasecatalyzed addition of ammonia to substituted cinnamic acids: a route to enantiopure $\alpha$ - and $\beta$-amino acids," Journal of Organic Chemistry, vol. 74, no. 23, pp. 9152-9157, 2009.

[32] T. Fukuyama, M. Arai, H. Matsubara, and I. Ryu, "MizorokiHeck arylation of $\alpha, \beta$-unsaturated acids with a hybrid fluorous ether, F-626: facile filtrative separation of products and efficient recycling of a reaction medium containing a catalyst," Journal of Organic Chemistry, vol. 69, no. 23, pp. 8105-8107, 2004.

[33] C. D. M. Duarte, H. Verli, J. X. D. Araújo-Júnior, I. A. D. Medeiros, E. J. Barreiro, and C. A. M. Fraga, "New optimized piperamide analogues with potent in vivo hypotensive properties," European Journal of Pharmaceutical Sciences, vol. 23, no. 4-5, pp. 363-369, 2004.

[34] D. R. Brittelli, "Phosphite-mediated in situ carboxyvinylation: a new general acrylic acid synthesis," Journal of Organic Chemistry, vol. 46, no. 12, pp. 2514-2520, 1981.

[35] M. Sharma, M. C. Joshi, V. Kumar, S. V. Malhotra, and D. S. Rawat, "Synthesis and anticancer activity of 13-membered cyclic enediynes," Archiv der Pharmazie, vol. 344, no. 9, pp. 564-571, 2011.

[36] M. Gupta, R. Gupta, and M. Anand, "Hydroxyapatite supported caesium carbonate as a new recyclable solid base catalyst for the Knoevenagel condensation in water," Beilstein Journal of Organic Chemistry, vol. 5, article A68, 2009.

[37] C. M. M. Santos, A. M. S. Silva, and J. A. S. Cavaleiro, "Efficient syntheses of new polyhydroxylated 2,3-diaryl-9H-xanthen-9ones," European Journal of Organic Chemistry, no. 16, pp. 26422660, 2009.

[38] N. Desideri, R. Fioravanti, L. P. Monaco et al., "1, 5-Diphenylpenta-2, 4-dien-1-ones as potent and selective monoamine oxidase-B inhibitors," European Journal of Medicinal Chemistry, vol. 59, pp. 91-100, 2013.

[39] “SAINT Version 7.60a," Bruker AXS Inc., Madison, Wis, USA, 2006.

[40] G. M. Sheldrick, "SHELXS-97, SHELXL-97 and SADABS version 2.05," University of Göttingen, Germany, 1997.

[41] L. J. Barbour, "X-seed-a software tool for supramolecular crystallography," Journal of Supramolecular Chemistry, vol. 1, no. 4-6, pp. 189-191, 2001.

[42] J. L. Atwood and L. J. Barbour, "Molecular graphics: from science to art," Crystal Growth and Design, vol. 3, no. 1, pp. 3-8, 2003.

[43] A. W. Bauer, W. M. Kirby, J. C. Sherris, and M. Turck, "Antibiotic susceptibility testing by a standardized single disk method," American Journal of Clinical Pathology, vol. 45, no. 4, pp. 493496, 1966. 

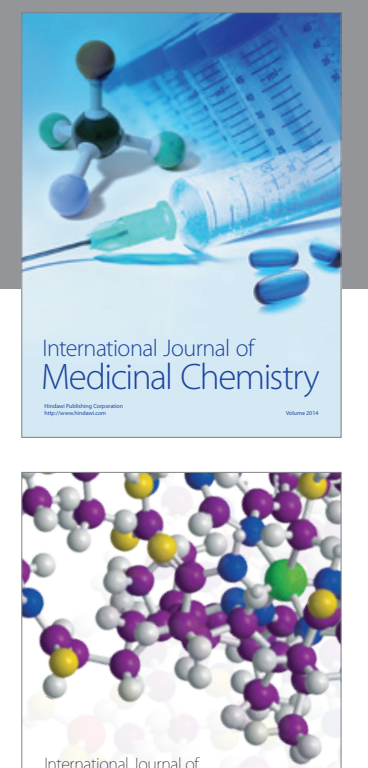

\section{Carbohydrate} Chemistry

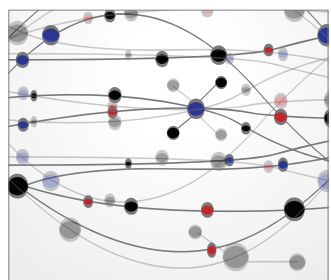

The Scientific World Journal
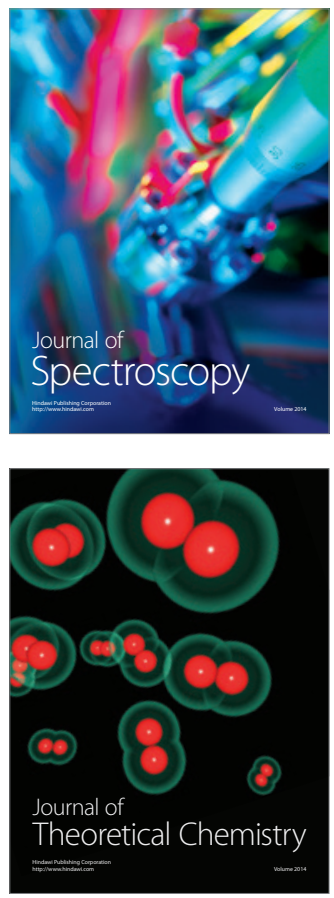
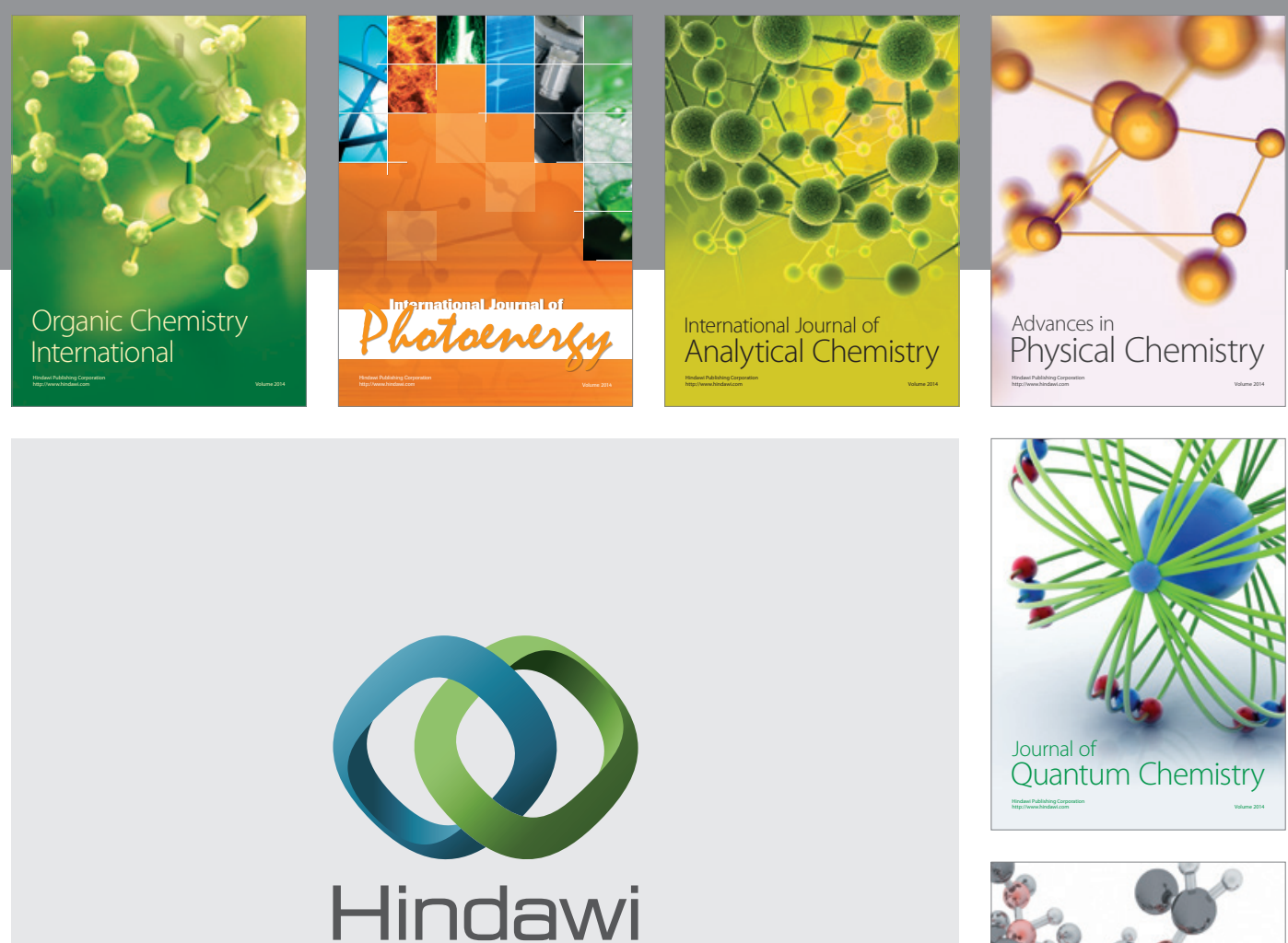

Submit your manuscripts at

http://www.hindawi.com

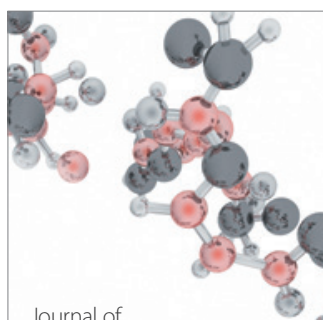

Analytical Methods

in Chemistry

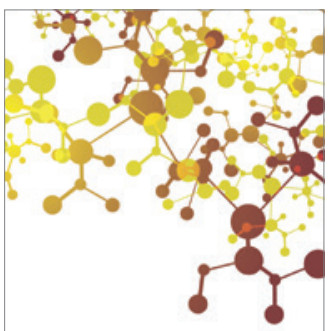

Journal of

Applied Chemistry

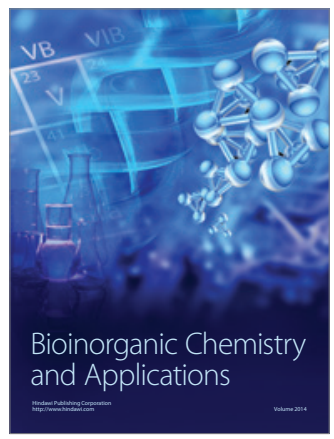

Inorganic Chemistry
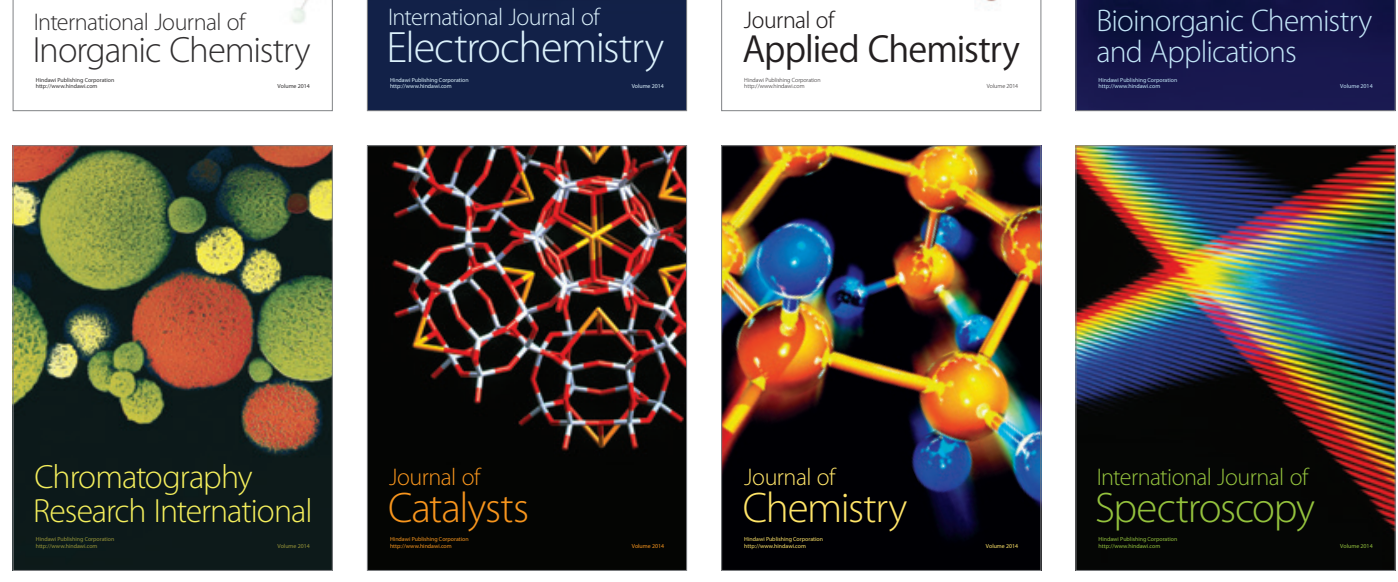